\title{
A process-based typology of hydrological drought
}

\section{A. F. Van Loon and H. A. J. Van Lanen}

Hydrology and Quantitative Water Management Group, Wageningen University, P.O. Box 47, 6700 AA, Wageningen, The Netherlands

Correspondence to: A. F. Van Loon (anne.vanloon@wur.nl)

Received: 1 December 2011 - Published in Hydrol. Earth Syst. Sci. Discuss.: 22 December 2011

Revised: 11 May 2012 - Accepted: 25 May 2012 - Published: 6 July 2012

\begin{abstract}
Hydrological drought events have very different causes and effects. Classifying these events into distinct types can be useful for both science and management. We propose a hydrological drought typology that is based on governing drought propagation processes derived from catchment-scale drought analysis. In this typology six hydrological drought types are distinguished, i.e. (i) classical rainfall deficit drought, (ii) rain-to-snowseason drought, (iii) wet-to-dry-season drought, (iv) cold snow season drought, (v) warm snow season drought, and (vi) composite drought. The processes underlying these drought types are the result of the interplay of temperature and precipitation at catchment scale in different seasons. As a test case, about 125 groundwater droughts and 210 discharge droughts in five contrasting headwater catchments in Europe have been classified. The most common drought type in all catchments was the classical rainfall deficit drought (almost $50 \%$ of all events), but in the selected catchments these were mostly minor events. If only the five most severe drought events of each catchment are considered, a shift towards more rain-to-snow-season droughts, warm snow season droughts, and composite droughts was found. The occurrence of hydrological drought types is determined by climate and catchment characteristics. The drought typology is transferable to other catchments, including outside Europe, because it is generic and based upon processes that occur around the world. A general framework is proposed to identify drought type occurrence in relation to climate and catchment characteristics.
\end{abstract}

\section{Introduction}

Hydrological drought events are severe natural disasters, in damage comparable to large-scale floods and earthquakes. Due to their long duration and large spatial extent, droughts have significant economic, social, and environmental impacts (EU, 2006, 2007; Sheffield and Wood, 2011). Especially in vulnerable regions like Asia and Africa, the total number of people affected by drought is very high (up to 300 million people per event; CRED, 2011), and droughts result in famine and loss of life (ISDR, 2007), as happened recently in the Horn of Africa (FEWS-NET, 2011; UN, 2011). Droughts in developed countries primarily result in economic loss. In the USA, economic loss due to drought amounts to on average 6 to 8 billion USD per year (Andreadis et al., 2005; Below et al., 2007) and in the EU, it was estimated at more than 100 billion EUR in the period 1976-2006 (EU, 2006, 2007). According to recent drought studies (EU, 2006, 2007; Sheffield, 2008; Feyen and Dankers, 2009; Dai, 2011), there is an increasing trend in drought extent and population affected by drought, which makes drought research and management a pressing issue.

Drought is defined as a sustained and regionally-extensive period of below-average natural water availability. It is a recurring and worldwide phenomenon, with spatial and temporal characteristics that vary significantly from one region to another (Tallaksen and Van Lanen, 2004). A prolonged lack of precipitation (also called meteorological drought) can propagate through the hydrological system and affect soil moisture, resulting in soil moisture drought, as well as groundwater and discharge, resulting in hydrological drought (Tallaksen and Van Lanen, 2004; Mishra and Singh, 2010).

This so-called propagation of drought from meteorological to hydrological drought is characterised by a number of 
features (Eltahir and Yeh, 1999; Peters et al., 2003; Van Lanen et al., 2004; Van Loon et al., 2011b), visualised in Fig. 1:

- meteorological droughts are combined into a prolonged hydrological drought (pooling);

- meteorological droughts are attenuated in the stores (attenuation);

- a lag occurs between meteorological, soil moisture, and hydrological drought (lag);

- droughts get longer moving from meteorological to soil moisture to hydrological drought (lengthening).

These features are controlled by catchment characteristics and climate. Lag and attenuation are governed by catchment control, and pooling and lengthening by both catchment and climate control (Van Lanen et al., 2004).

Compared to other natural disasters, knowledge of drought still has large gaps (Smakhtin, 2001; Mishra and Singh, 2010). Most focus of drought research is on finding the "best" drought index (e.g. Bonacci, 1993; Heim, 2002; Keyantash and Dracup, 2002; Ntale and Gan, 2003; Mpelasoka et al., 2008; Niemeyer, 2008; Wanders et al., 2010), but hydrological droughts have very different causes that cannot be captured by a single index (Wanders et al., 2010). Besides by a rainfall deficit, hydrological droughts can also be caused by low temperatures and snow accumulation (Van Lanen et al., 2004; Van Loon et al., 2010). In 2006 and 2010, for example, cold and dry winters have resulted in severe problems with drinking water and electricity production in Norway (NRK, 2010).

For drought management, it is very important to distinguish between different types of hydrological drought, because these different types need different preventing measures and coping mechanisms. In addition, drought research could benefit from a common terminology and further study of the processes underlying drought. Therefore, one of the most important scientific challenges is related to the diversity of causative mechanisms of hydrological drought around the world (Marsh et al., 2007). Currently, there is no generally accepted classification scheme for hydrological droughts (Wilhite and Glantz, 1985; Lloyd-Hughes and Saunders, 2002), like there is for floods (Merz and Blöschl, 2003). Hydrological drought classification is mainly done for sectors (e.g. socio-economic drought; Mishra and Singh, 2010) and based on drought severity (Dracup et al., 1980; Rossi et al., 1992; McKee et al., 1993, 1995; Lloyd-Hughes and Saunders, 2002; Smakhtin and Hughes, 2004), but not based on processes. For meteorological droughts, some process-based classifications have been developed (Phillips and McGregor, 1998; Fowler and Kilsby, 2002; Mishra and Singh, 2010), but hydrological drought events are either defined in very general terms and analysed only by their statistics (Andreadis et al., 2005; Fleig et al., 2006; Sheffield and Wood, 2007; Sheffield, 2008; Sheffield et al., 2009) or a single drought event with its

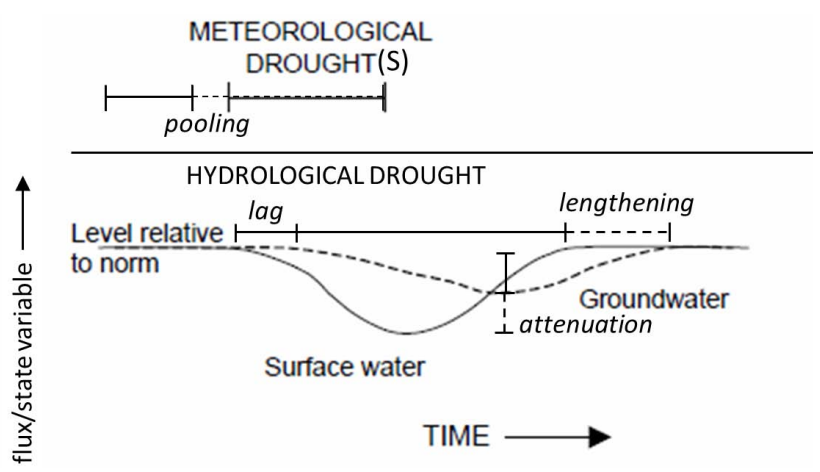

Fig. 1. Features characterising propagation of meteorological drought(s) to hydrological drought: pooling, lag, attenuation, and lengthening (modified from Hisdal and Tallaksen, 2000).

underlying processes is described in detail (e.g. Santos et al., 2007; Trigo et al., 2010; Li et al., 2010). A more generally applicable typology of hydrological drought is needed, both for process understanding of drought propagation and for improvement of drought forecasting and management.

In this paper, we propose a general hydrological drought typology based on the underlying processes of drought propagation. These governing processes were derived from time series investigation (observed and/or simulated) and drought analysis in selected catchments with contrasting characteristics. Therefore, the resulting typology is applicable to other catchments around the world where observed and/or simulated hydro-meteorological data are available. The objectives of this study are: (i) to describe hydrological drought types and provide examples, (ii) to show the application of the drought typology by classifying hydrological drought events in five contrasting catchments, (iii) to find the most common and most severe drought types in catchments with different climate and catchment characteristics, and (iv) to relate these drought types to catchment and climate control.

The outline of the paper is focussed on the hydrological drought typology, which is presented in Sect. 4 and applied in Sect. 5. The drought types defined are the result of detailed studies of drought events in five contrasting study areas (Sect. 2), which were analysed using a hydrological model (Sect. 3.1) and a drought analysis method (Sect. 3.2). Finally, in Sects. 6 and 7, results are discussed and summarised and a general framework is presented that shows the occurrence of drought types in relation to climate and catchment characteristics.

\section{Study areas}

The five catchments used in this study are natural headwater catchments in Europe with contrasting climate and catchment characteristics (Fig. 2a; Van Lanen et al., 2008). 


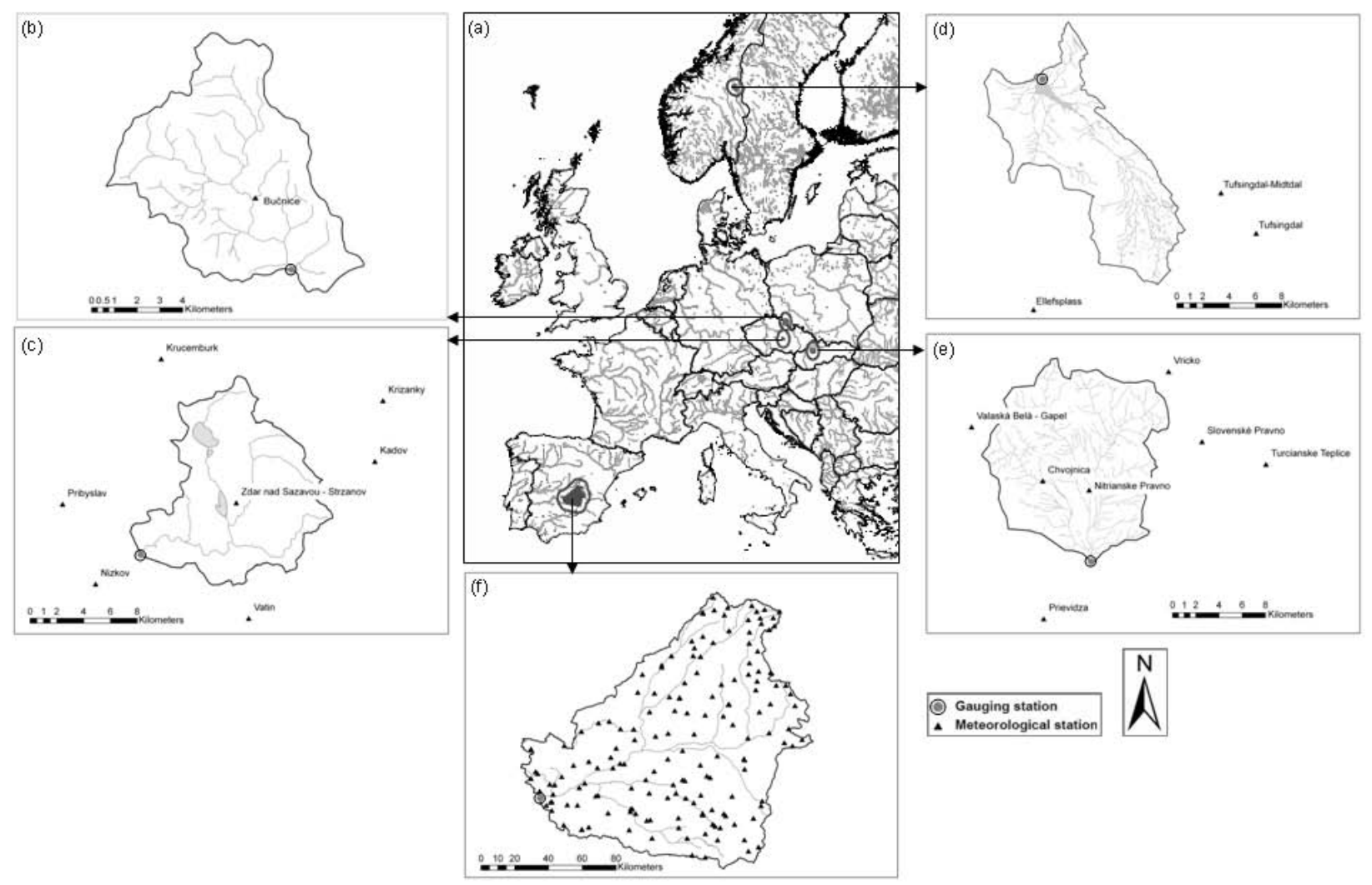

Fig. 2. (a) Location of the selected catchments in Europe, including gauging station and meteorological stations; (b) Upper-Metuje catchment; (c) Upper-Sázava catchment; (d) Narsjø catchment; (e) Nedožery catchment; and (f) Upper-Guadiana catchment.

\subsection{Narsjø}

The Narsjø catchment is located in southeastern Norway (Fig. 2d). It is a sub-basin of the Upper-Glomma, which is the headwater catchment of the Glomma. The area of the Narsjø catchment is approximately $120 \mathrm{~km}^{2}$ (Table 1). The catchment is located in a glacially formed mountainous region with rounded tops and U-shaped valleys. The altitude range is rather large with approximately $740-1600 \mathrm{~m}$ a.m.s.l. (Engeland, 2002). The Narsjø catchment has a subarctic climate with mild summers and very cold winters (KöppenGeiger climate Dfc). In the observation period 1958-2007, measured mean annual temperature was $0.7^{\circ} \mathrm{C}$, precipitation was around $590 \mathrm{~mm} \mathrm{yr}^{-1}$, and potential evaporation was around $300 \mathrm{~mm} \mathrm{yr}^{-1}$ (Table 1). In winter, a continuous snow cover is present for, on average, 7 months from mid-October until the end of May, dependent on altitude (Engeland, 2002). Measured mean discharge was around $820 \mathrm{~mm} \mathrm{yr}^{-1}$, which is higher than measured precipitation due to the low elevation of precipitation gauges (Fig. 2d) in combination with an increase of precipitation with altitude. The low-flow season of Narsjø is winter, when recharge is zero because of snow accumulation, and highest flows occur in May due to snow melt (Table 1). Narsjø is a hardrock catchment consisting predominantly of impermeable metamorphic rocks without extensive groundwater storage, which makes the catchment quickly respond to precipitation. Some delay in the response is caused by lakes, covering $3 \%$ of the catchment, and bogs, covering $12 \%$ (Van Loon et al., 2010). Other land cover types of the catchment are open area $(61 \%)$, forest $(24 \%)$, and only a little agriculture $(0.4 \%)$ (Hohenrainer, 2008). Human influence is very limited in the Narsjø catchment.

\subsection{Upper-Metuje}

The Upper-Metuje catchment is located in northeastern Czech Republic and partly in Poland (approximately $10 \%$ of the catchment area) (Fig. 2b). It is the headwater catchment of the Metuje, which drains into the Elbe. The area of the Upper-Metuje catchment is approximately $70 \mathrm{~km}^{2}(\mathrm{Ta}-$ ble 1). The catchment is located in a hilly region of gentle slopes and wide valleys, except for some steep sandstone formations in the centre of the catchment. The altitude range is approximately $450-780 \mathrm{~m}$ a.m.s.l. The UpperMetuje catchment has an oceanic climate with mild summers and winters (Köppen-Geiger climate $\mathrm{Cfb}$ ). In the observation period 1982-2005, measured mean annual temperature was $5.9^{\circ} \mathrm{C}$, precipitation was around $750 \mathrm{~mm} \mathrm{yr}^{-1}$, and potential evaporation was around $570 \mathrm{~mm} \mathrm{yr}^{-1}$ (Table 1). In winter, a continuous snow cover is present for, on average, 
Table 1. Catchment characteristics of the selected catchments Narsjø (Norway), Upper-Metuje and Upper-Sázava (Czech Republic), Nedožery (Slovakia), and Upper-Guadiana (Spain); obs. period = observation period, $T=$ temperature, $P=$ precipitation, PET $=$ potential evaporation, $Q=$ discharge.

\begin{tabular}{|c|c|c|c|c|c|}
\hline & Narsjø & Upper-Metuje & Upper-Sázava & Nedožery & Upper-Guadiana \\
\hline Area $\left[\mathrm{km}^{2}\right]$ & 119 & 73.6 & 131 & 181 & 16,479 \\
\hline Altitude [m a.m.s.l. $]^{\mathrm{a}}$ & $945(737-1595)$ & $591(459-780)$ & $628(487-805)$ & $573(288-1172)$ & 769 (599-1100) \\
\hline Climate type $[-]$ & Dfc & $\mathrm{Cfb}$ & $\mathrm{Cfb}$ & $\mathrm{Dfb}$ & Csa, Csb and Bsk \\
\hline Obs. period & 1958-2007 & 1982-2005 & 1963-1999 & 1974-2006 & 1960-2001 \\
\hline$T\left[{ }^{\circ} \mathrm{C}\right]$ & 0.7 & 5.9 & 6.8 & 7.6 & 14.1 \\
\hline$\left[{ }^{\circ} \mathrm{C}\right]^{\mathrm{b}}$ & Jan: -10.1; Jul: 11.9 & Jan: -3.9 ; Jul: 15.5 & Jan: $-3.2 ;$ Jul: 16.3 & Jan: -2.8; Jul: 17.5 & Jan: 5.1; Jul: 25.0 \\
\hline$P\left[\mathrm{~mm} \mathrm{yr}^{-1}\right]$ & 594 & 746 & 717 & 873 & 450 \\
\hline$\left[\mathrm{mm} \text { month }^{-1}\right]^{\mathrm{b}}$ & Mar: 27; Jul: 81 & Apr: 42; Jul: 92 & Feb: 36; Jun: 92 & Feb: 52; Jun: 96 & Jul: 9; Dec: 54 \\
\hline $\operatorname{PET}\left[\mathrm{mm} \mathrm{yr}^{-1}\right]$ & 296 & 574 & 684 & 981 & 1250 \\
\hline$Q\left[\mathrm{~mm} \mathrm{yr}^{-1}\right]$ & 820 & 321 & 291 & 352 & 16 \\
\hline$\left[\mathrm{mm} \mathrm{d}^{-1}\right]^{\mathrm{b}}$ & Mar: 0.29; May: 8.0 & Oct: $0.66 ;$ Mar: 1.9 & Aug: 0.48; Mar: 1.7 & Aug: 0.42; Mar: 2.1 & Sep: 0.009; Feb: 0.11 \\
\hline
\end{tabular}

${ }^{a}=\operatorname{mean}(\min -\max ) .{ }^{b}=\min$ monthly; max monthly

4 months from December until the beginning of April. Measured mean discharge was around $320 \mathrm{~mm} \mathrm{yr}^{-1}$. The lowflow season of Upper-Metuje is summer/autumn, and highest flows occur in March due to snow melt (Table 1). UpperMetuje is a groundwater catchment consisting of multiple sandstone layers, alternating with less permeable sediment layers, that form a large, multiple aquifer system. This makes it a slowly responding catchment with a relatively high baseflow. Nevertheless, discharge peaks occur when storage is filled (Van Loon et al., 2010). Land cover of the catchment mainly consists of cropland and grassland (51\%), and forest (46\%) (Rakovec et al., 2009). Human influence is limited to extensive agriculture.

\subsection{Upper-Sázava}

The Upper-Sázava catchment is located in central Czech Republic (Fig. 2c). It is the headwater catchment of the Sázava, which (finally) drains into the Elbe. The area of the UpperSázava catchment is approximately $130 \mathrm{~km}^{2}$ (Table 1). The catchment is located in a hilly region of gentle slopes and wide valleys and the altitude range is approximately 490$800 \mathrm{~m}$ a.m.s.l. The Upper-Sázava catchment has an oceanic climate with mild summers and winters (Köppen-Geiger climate $\mathrm{Cfb}$ ). In the observation period 1963-1999, measured mean annual temperature was $6.8^{\circ} \mathrm{C}$, precipitation was around $720 \mathrm{~mm} \mathrm{yr}^{-1}$, and potential evaporation was around $680 \mathrm{~mm} \mathrm{yr}^{-1}$ (Table 1). In winter, a continuous snow cover is present for, on average, 4 months from December until the beginning of April. Measured mean discharge was around $290 \mathrm{~mm} \mathrm{yr}^{-1}$. The low-flow season of Upper-Sázava is summer, and highest flows occur in March due to snow melt (Table 1). Upper-Sázava is a hardrock catchment consisting of impermeable metamorphic rocks and sedimentary rocks with limited groundwater storage, which gives it an intermediate response to precipitation. A significant delay is caused by lakes, covering around $2 \%$ of the catchment area (Van Loon et al., 2010). Other land cover types of the catchment are forest (50\%), and cropland and grassland (40\%) (Rakovec et al., 2009). Human influence is limited to extensive agriculture, and some groundwater extraction and sewage disposal.

\subsection{Nedožery}

The Nedožery catchment is located in central Slovakia (Fig. 2e). It is the headwater catchment of the Nitra, which (finally) drains into the Danube. The area of the Nedožery catchment is approximately $180 \mathrm{~km}^{2}$ (Table 1). The catchment is located in a mountainous region with steep slopes. Therefore, the altitude range is large, from approximately 290-1170 m a.m.s.l. The catchment has a humid continental climate with warm summers and cool winters (KöppenGeiger climate Dfb). In the observation period 1974-2006, measured mean annual temperature was $7.6^{\circ} \mathrm{C}$, precipitation was around $870 \mathrm{~mm} \mathrm{yr}^{-1}$, and potential evaporation was around $980 \mathrm{~mm} \mathrm{yr}^{-1}$ (Table 1). In winter, a continuous snow cover is present for, on average, 4 months from December until the beginning of April, with large variation within the catchment due to elevation. Measured mean discharge was around $350 \mathrm{~mm} \mathrm{yr}^{-1}$. The low-flow season of Nedožery is summer, and highest flows occur in March due to snow melt (Table 1). Nedožery is a hardrock catchment consisting predominantly of impermeable metamorphic rocks without extensive groundwater storage, which makes it quick in responding to precipitation. The presence of steep slopes and absence of bogs or lakes accelerates the response (Van Loon et al., 2010). Two-thirds of the catchment is covered by forest. Other land cover types are agriculture (23\%), natural meadow (6\%), and urban area (5\%) (Oosterwijket al., 2009). Human influence is limited to extensive agriculture. 


\subsection{Upper-Guadiana}

The Upper-Guadiana catchment is located in central Spain (Fig. 2f). It is the headwater catchment of the Guadiana. The area of the Upper-Guadiana catchment is approximately $16480 \mathrm{~km}^{2}$, which is considerably larger than the other catchments (Table 1). This larger area is chosen to rule out any significantgroundwater transport over the catchment boundary and to ensure a good quality of discharge measurement (Veenstra, 2009). The larger catchment area is not expected to influence the studied drought propagation processes on which the proposed typology is based. The UpperGuadiana catchment is part of the Central Spanish Plateau. The altitude range is approximately $600-1100 \mathrm{~m}$ a.m.s.l., and especially in the centre topography is rather flat. The Upper-Guadiana catchment has a Mediterranean and semiarid climate with very warm summers and mild winters (Köppen-Geiger climate Csa, Csb and Bsk; Acreman, 2000). In the observation period 1960-2001, catchment-average measured mean annual temperature was $14.1^{\circ} \mathrm{C}$, precipitation was $450 \mathrm{~mm} \mathrm{yr}^{-1}$, and potential evaporation was around $1250 \mathrm{~mm} \mathrm{yr}^{-1}$ (Table 1). In winter, no continuous snow cover is present. Only in very cold years some snow accumulation occurs in the highest parts of the catchment. Potential evaporation exceeds precipitation, resulting in a relatively low measured mean discharge of $16 \mathrm{~mm} \mathrm{yr}^{-1}$ (de la Hera, 1998). The low-flow season of Upper-Guadiana is summer due to a lack of recharge in this period, and highest flows occur in winter (Table 1). Upper-Guadiana is a groundwater catchment consisting of various areas with multiple layers of sedimentary rock (mainly gravel, limestone) forming large aquifer systems. This makes it a slowly responding catchment with most of the runoff discharged as baseflow. A number of interconnected wetlands cause further delay in the response to precipitation. Land use in the Upper-Guadiana catchment is mainly agricultural. Since 1970-1980, agriculture intensified and human influence (i.e. irrigation) in the catchment increased dramatically, causing declining groundwater levels and wetland area, and decreasing discharge (Veenstra, 2009).

\section{Modelling and drought analysis}

Long time series of observations of all hydro-meteorological variables were not available for the selected catchments, hence modelling was needed. Simulating low flows is a challenge. Smakhtin (2001) describes a number of difficulties in the modelling of low flows and Staudinger et al. (2011) state that "low flows are often poorly reproduced by commonly used hydrological models, which are traditionally designed to meet peak flow situations". For that reason, we used a model that has proven to be robust in low-flow situations (Te Linde et al., 2008; Driessen et al., 2010), and a calibration criterion that is especially focused on low flows (both described in Sect. 3.1). On the simulated hydrometeorological variables, we performed a drought analysis with the well-known threshold level method. This method and the results obtained are explained in Sect. 3.2.

\subsection{Hydrological modelling}

\subsubsection{HBV}

The conceptual, semi-distributed rainfall-runoff model HBV (Seibert, 1997) was chosen as hydrological model for this research. The original HBV model was developed in the early 1970s by Bergström $(1976,1995)$. Afterwards, different versions of HBV have been developed for both research and operational management. Although it was originally developed for Scandinavian conditions, the HBV model has been widely used in general modelling studies (Lindström, 1997; Uhlenbrook et al., 1999; Perrin et al., 2001; Oudin et al., 2005); in catchments in Europe: Austria (Merz and Blöschl, 2004), Belgium (Van Pelt et al., 2009; Driessen et al., 2010), Germany (Uhlenbrook et al., 1999; Nützmann and Mey, 2007), Sweden (Seibert, 1999; Seibert et al., 2003), and Ireland (Wang et al., 2006); and in other areas around the world, for example the Hindukush-Karakorum-Himalaya region (Akhtar et al., 2008) and selected catchments in Africa and South-America (Lidén and Harlin, 2000). In this research, we used the HBV model version developed by Seibert (1997, 2005). Seibert called it "HBV light", but for reasons of brevity it is referred to as "HBV" in the rest of this paper.

HBV simulates daily discharge from daily precipitation and temperature, and monthly or daily estimates of potential evaporation. The model consists of four routines, i.e. a distributed snow routine and soil moisture routine, a lumped response routine, and a routing routine (Fig. 3). Snow accumulation and melt are calculated by the degree-day method for a number of elevation (maximum 10) and vegetation (maximum 3) zones separately. In each of these zones, groundwater recharge and actual evaporation are functions of actual water storage in the soil box. Subsequently, the lumped response function, in the STANDARD version consisting of two linear reservoirs in series, transforms recharge into discharge. Finally, channel routing is computed by a triangular weighting function. Further description of the model can be found in Seibert (2000, 2005).

Since according to Seibert $(2000,2005)$ the DELAY response routine is better suited for modelling slowly responding deep-groundwater catchments, we tested this version besides the STANDARD response routine. The DELAY response routine consists of two linear reservoirs in parallel, of which the lower reservoir is preceded by a distribution of recharge over different delay boxes (Fig. 3).

The HBV model was forced with observed meteorological data of the selected catchments. Temperature and precipitation data were taken from meteorological stations inside or around the catchment (Fig. 2), and, if needed, averaged 


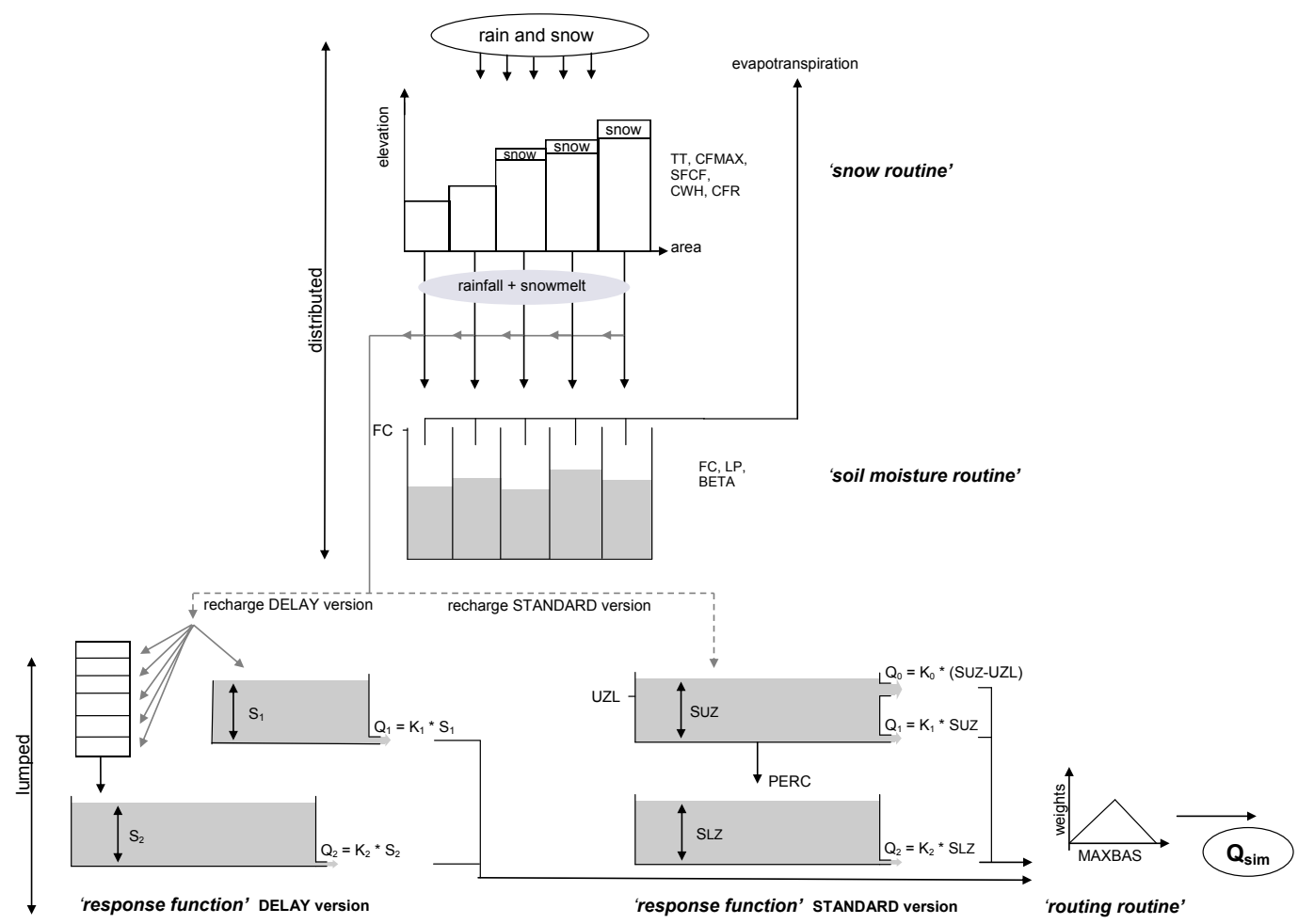

Fig. 3. Structure of the HBV model with two versions for the response routine: on the right-hand side the STANDARD version, and on the left-hand side the DELAY version (adapted from Seibert, 2000 and Oosterwijket al., 2009).

using Thiessen polygons. An altitude correction was applied to get correct input data for the elevation zones. Potential evaporation was calculated using the FAO Penman-Monteith method described by Allen et al. (1998). Due to different data availability and quality in each catchment, slightly different calculation procedures were followed according to the assumptions and recommendations described by Doorenbos and Pruitt (1975) and Allen et al. (1998).

\subsubsection{Calibration and validation}

Parameter values of HBV were determined by calibration. Calibration was done on observed discharge using the genetic calibration algorithm described by Seibert (2000). The agreement between simulated and observed discharge was evaluated by the Nash-Sutcliffe efficiency (Nash and Sutcliffe, 1970) based on the logarithm of observed and simulated discharge (ln Reff) (Seibert, 1999, 2005). The NashSutcliffe efficiency based on the logarithm of observed and simulated discharge is regarded as the best objective function for low-flow modelling (Krause et al., 2005). The entire observation period (Table 1) was used as calibration period for all catchments except Upper-Guadiana. Due to the strong human influence in that catchment after 1980 (see Sect. 2.5), the calibration period was restricted to the period 1960-1970, and the period 1970-1980 was used for validation. By calibrating the model with the undisturbed period and applying
Table 2. Nash-Sutcliffe values per catchment.

\begin{tabular}{lcc}
\hline & Reff & ln Reff \\
\hline Narsjø & 0.77 & 0.90 \\
Upper-Metuje & 0.51 & 0.69 \\
Upper-Sázava & 0.59 & 0.63 \\
Nedožery & 0.64 & 0.68 \\
Upper-Guadiana & 0.54 & 0.71 \\
\hline
\end{tabular}

this calibrated model to the disturbed period, we could naturalize the discharge of the disturbed period (Van Loon and Van Lanen, 2012). The drawback is that, when studying time series or drought characteristics for the disturbed period, simulations can not be compared to observations any more.

After calibration, all selected catchments were modelled reasonably well with HBV (Table 2). In general, ln Reff values were (slightly) higher than Reff values, because calibration was based on ln Reff. This indicates a good performance of the model on low flows. Further validation of the HBV model results, including graphs and tables of simulated vs. observed discharge and groundwater, are given in Appendix A. The results of calibration and validation of the HBV model justify the use of simulated fluxes and state variables for drought analysis. 
Several output variables of HBV were used for further drought analysis, i.e. catchment average precipitation (elevation corrected) in $\mathrm{mm} \mathrm{d}^{-1}$, soil moisture storage in $\mathrm{mm}$, groundwater storage in $\mathrm{mm}$, and discharge in $\mathrm{mm} \mathrm{d}^{-1}$. For groundwater storage we used only storage in the lower groundwater reservoir (ULZ, see Fig. 3), which represents deep groundwater. The reason for not including storage in the upper reservoir is that the fast flow paths in HBV (e.g. surface runoff) are modelled through this upper reservoir; hence it does not represent real groundwater storage (Fig. 3).

\subsection{Drought analysis}

\subsubsection{Threshold level method}

To determine droughts from hydro-meteorological time series, the threshold level method (Yevjevich, 1967; Hisdal et al., 2004) was applied. With this method, a drought occurs when the variable of interest (i.e. precipitation, soil moisture, groundwater storage, or discharge) is below a predefined threshold (Fig. 4). A drought event starts when the variable falls below the threshold level and the event continues until the threshold is exceeded again. Each drought event can be characterised by its duration and by some measure of the severity of the event. For fluxes (i.e. precipitation and discharge) the most commonly used severity measure is deficit volume, calculated by summing up the differences between actual flux and the threshold level over the drought period (Hisdal et al., 2004; Fleig et al., 2006). For state variables (i.e. soil moisture and groundwater storage), we used the maximum deviation from the threshold (maximum deviation) as the severity measure (Fig. 4).

Either a fixed or a variable (seasonal, monthly, or daily) threshold can be used. In this study, a variable threshold was chosen, as seasonal patterns are then taken into account. For drought management, not only is the yearly recurring (summer or winter) low-flow period important, but any deviation from the normal seasonal pattern (see definition of drought in Sect. 1). Furthermore, a variable threshold shows deficiencies in the high-flow season that can lead to a drought in the low-flow season (Hisdal and Tallaksen, 2000). We applied a monthly threshold derived from the 80th percentile of the monthly duration curves. This implies that for each month a value of a flux or state variable is chosen that is exceeded $80 \%$ of the time in a specific month. The chosen 80th percentile lays within the range of 70th-95th percentile commonly used in drought studies for perennial rivers (e.g. Hisdal et al., 2001, 2004; Andreadis et al., 2005; Fleig et al., 2006; Tallaksen et al., 2009; Wong et al., 2011). The choice of a different percentile in the calculation of the threshold level changes drought characteristics. For example, with a 95th percentile threshold fewer events with shorter durations and lower deficit volumes and maximum deviations are identified, and with a 70th percentile threshold the opposite. However, the relation between drought characteristics of the

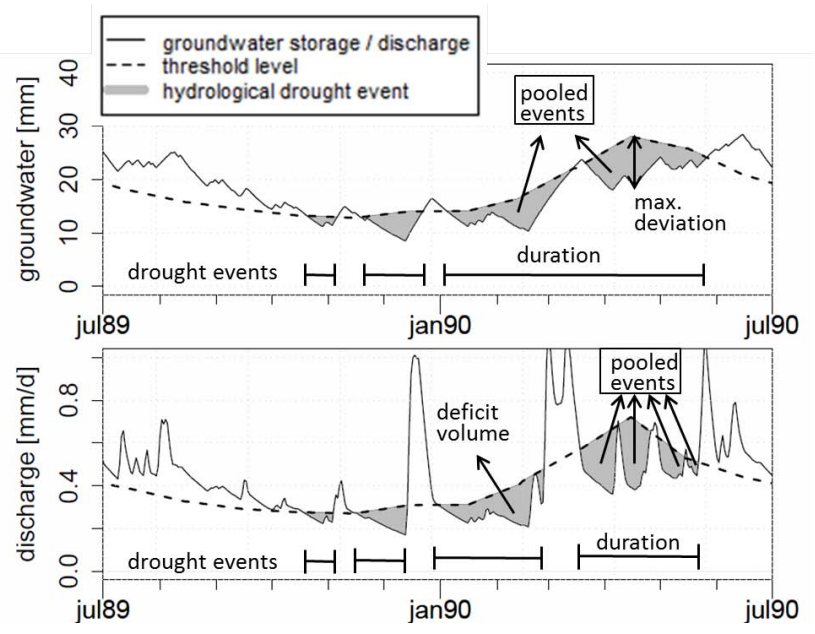

Fig. 4. Threshold level method with variable threshold (80th percentile of monthly duration curve, smoothed by 30-day moving average) for groundwater storage (upper panel) and discharge (lower panel), including an illustration of pooling method and drought characteristics duration, deficit volume, and maximum deviation.

variables does not change. This is shown, amongst others, by Oosterwijket al. (2009). Furthermore, the drought typology that is based on this drought analysis will not change when using a different threshold, because the same processes that cause drought using an 80th percentile will be present when using a 95 th or a 70 th percentile.

For the Upper-Guadiana catchment, the threshold values were calculated based on the period 1960-1980 and applied to the entire time series to eliminate the strong human impact after 1980 (see Sect. 2.5). For the other catchments, the entire observation period (Table 1) was used for the calculation of the threshold. The discrete monthly threshold values were smoothed by applying a centred moving average of 30 days. After application of the threshold level method, mutually dependent droughts were pooled using the inter-event time method (Fleig et al., 2006). An inter-event time period of 10 days was used for all catchments, based on the range given by Tallaksen et al. (1997) and Fleig et al. (2006). The inter-event time period is quite a subjective parameter. Tallaksen et al. (1997) and Fleig et al. (2006) tested a number of inter-event time options for a representative sample of catchments around the world (taken from a global dataset) and concluded that the sensitivity curves generally started to level out around 5 days, and for most streams the deficit characteristics did not change substantially after 10 to 15 days, implying that a maximum of pooling was obtained. Other studies used an inter-event time period of 2 days (Engeland et al., 2004), 6 days (Tate and Freeman, 2000), and 30 days (Pandey et al., 2008). In this study, we have chosen 10 days, which is quite a conservative number. This minimizes the occurrence of dependent drought events, but should not include too long 
high peaks in a drought event. The choice of the inter-event time period is not expected to change the results of this study.

The calculation of drought characteristics of the pooled drought events (visualised in Fig. 4) is done according to Zelenhasić and Salvai (1987):

- pooled duration $=$ duration $_{i}+$ duration $_{i+1}+\ldots$

- pooled deficit volume $=$ deficit volume $_{i}+$ deficit volume $_{i+1}+\ldots$

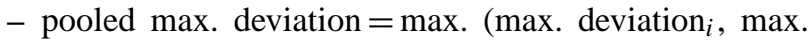
deviation $\left._{i+1}, \ldots\right)$

where $i$ is a hydrological drought event and $i+1$ is the following hydrological drought event.

To eliminate minor droughts, all drought events with a duration less than 15 days were excluded from the analysis (values up to 5 days are used by Hisdal et al., 2004; Birkel, 2005; Fleig et al., 2006; Van Loon et al., 2011a, but various studies showed that minor droughts can have durations up to 20 days; Hisdal, 2002; Fleig et al., 2005; Kaznowska and Banasik, 2011; Kim et al., 2011). Of the remaining drought events, a few were found to be not real drought events, but rather artefacts of the method used. A very sharp increase in discharge in combination with a gradually rising threshold level can result in a few days of below-threshold levels. This happens in catchments with a pronounced difference between wet and dry season, such as catchments with a pronounced snow melt peak or catchments with a monsoon climate. These events are not related to a rainfall deficit or temperature difference (so not caused by meteorological anomaly as defined by Stahl and Hisdal, 2004), but are purely a consequence of the smooth threshold level in combination with a sharp increase in groundwater storage or discharge. Therefore, in this research we did not consider these events as drought but rather as anomaly. In this research, such anomalies were only found in the Narsjø catchment (4\% of all events in groundwater and $7 \%$ of all events in discharge). This is due to the very sharp increase in discharge during the snow melt season. In the other catchments with snow (UpperMetuje, Upper-Sázava, and Nedožery) no such anomalies were found, because winters are less severe in those catchments, resulting in a less abrupt transition from winter to summer. As we did not study catchments with a monsoon climate, we did not find anomalies related to a sudden increase in precipitation. In the rest of this paper, these anomalies are disregarded and focus is only on droughts.

\subsubsection{Drought characteristics}

General drought characteristics of all study catchments are displayed in Table 3. The drought events of simulated and observed discharge showed similar characteristics (especially regarding number of drought events and mean duration), again indicating the reasonable performance of the HBV model on low flows. Only in the Upper-Guadiana catchment did drought characteristics of simulated discharge deviate significantly from those of observed discharge. In this catchment observations and simulations can not be compared, as is explained in Sect. 3.1. The reason is that drought characteristics of this catchment were calculated for the entire observation period (1960-2001), including the period with strong human influence (Sect. 2.5). The drought characteristics of observed discharge reflect this disturbed situation, while those of simulated discharge represent a situation without human influence (as HBV does not simulate human influence, because it is calibrated on natural flows).

Table 3 confirms what is known about propagation in drought characteristics (Di Domenico et al., 2010; Van Loon et al., 2011b):

- Drought events become fewer and longer when moving from precipitation via soil moisture to groundwater storage, so the number of droughts decreases and duration increases.

- Drought events in discharge have drought characteristics comparable to those of soil moisture, because they reflect both fast and slow pathways in a catchment.

- In fast reacting systems (like Narsjø and Nedožery), discharge drought characteristics are more comparable to those of precipitation (more and shorter); in slowly reacting systems (like Upper-Metuje and UpperGuadiana) discharge drought characteristics are more comparable to those of groundwater storage (fewer and longer).

- Deficit volumes are higher for droughts in precipitation than for discharge droughts, because precipitation is higher and more variable, resulting in higher threshold values and a larger deviation from the threshold.

- Mean maximum deviation is higher for soil moisture droughts than for droughts in groundwater, because soil moisture values are much more variable, while in groundwater the signal is smoothed. In the drought characteristics of the Narsjø catchment this effect is not visible, because soil water storage is limited in this catchment due to very coarse, shallow soils.

The Narsjø and Nedožery catchments have similar drought characteristics because they are both fast reacting (Table 3). Narsjø is a bit slower (fewer, but longer groundwater droughts) due to the presence of bogs and lakes that slightly delay the response to precipitation. The Upper-Metuje and Upper-Sázava catchments have similar drought characteristics because they are both slow reacting (Table 3). UpperMetuje has an aquifer system with high storage and UpperSázava has many lakes that delay the response. The UpperGuadiana catchment has very long hydrological droughts (groundwater drought events of, on average, more than two 
Table 3. General drought characteristics using an $80 \%$ monthly threshold (moving average 30 days), the inter-event time method for pooling, and a minimum drought duration of 15 days for the hydro-meteorological variables simulated with HBV and observed discharge for all selected catchments.

\begin{tabular}{|c|c|c|c|c|c|}
\hline & & $\begin{array}{r}\text { No. of droughts } \\
\text { [per year] }\end{array}$ & $\begin{array}{r}\text { Mean duration } \\
\text { [day] }\end{array}$ & $\begin{array}{r}\text { Mean deficit } \\
{[\mathrm{mm}]}\end{array}$ & $\begin{array}{l}\text { Mean maximum } \\
\text { deviation }[\mathrm{mm}]\end{array}$ \\
\hline \multirow[t]{5}{*}{ Narsjø } & catchment precipitation & 1.8 & 34 & 13.6 & - \\
\hline & soil moisture & 1.1 & 59 & - & 7.4 \\
\hline & groundwater storage & 0.9 & 68 & - & 7.3 \\
\hline & simulated discharge & 1.2 & 56 & 11.7 & - \\
\hline & observed discharge & 1.2 & 54 & 17.5 & - \\
\hline \multirow[t]{5}{*}{ Upper-Metuje } & catchment precipitation & 1.7 & 33 & 14.2 & - \\
\hline & soil moisture & 1.2 & 45 & - & 15.2 \\
\hline & groundwater storage & 0.6 & 112 & - & 11.3 \\
\hline & simulated discharge & 1.0 & 60 & 3.2 & - \\
\hline & observed discharge & 1.2 & 53 & 4.5 & - \\
\hline \multirow[t]{5}{*}{ Upper-Sázava } & catchment precipitation & 2.0 & 30 & 12.5 & - \\
\hline & soil moisture & 1.3 & 47 & - & 18.3 \\
\hline & groundwater storage & 0.5 & 139 & - & 8.1 \\
\hline & simulated discharge & 1.1 & 62 & 3.6 & - \\
\hline & observed discharge & 1.1 & 58 & 5.6 & - \\
\hline \multirow[t]{5}{*}{ Nedožery } & catchment precipitation & 1.6 & 34 & 16.5 & - \\
\hline & soil moisture & 1.4 & 43 & - & 22.4 \\
\hline & groundwater storage & 1.1 & 59 & - & 5.3 \\
\hline & simulated discharge & 1.3 & 50 & 4.6 & - \\
\hline & observed discharge & 1.4 & 45 & 4.5 & - \\
\hline \multirow[t]{5}{*}{ Upper-Guadiana } & catchment precipitation & 2.0 & 40 & 10.9 & - \\
\hline & soil moisture & 1.2 & 77 & - & 21.9 \\
\hline & groundwater storage & 0.2 & 756 & - & 5.9 \\
\hline & simulated discharge & 1.0 & 154 & 2.2 & - \\
\hline & observed discharge & 0.7 & 253 & 5.5 & - \\
\hline
\end{tabular}

years; Table 3). This is due to its very slow response to precipitation caused by the presence of extensive aquifer systems and wetlands, and to its dry climate.

The numbers in Table 3 show some differences between catchments that indicate propagation processes, but for a thorough insight into drought generating mechanisms time series of all hydro-meteorological variables need to be studied in detail.

\section{Typology of hydrological droughts}

Based on an in-depth analysis of time series of hydrometeorological variables of the study catchments, a hydrological drought typology is proposed that uses the diversity of drought generating mechanisms as the basic principle.

The following hydrological drought types are distinguished:

- classical rainfall deficit drought;

- rain-to-snow-season drought;

- wet-to-dry-season drought;
- cold snow season drought;

- warm snow season drought;

- composite drought.

For each of these drought types, generating mechanisms are described below and examples are presented.

\subsection{Classical rainfall deficit drought}

The classical rainfall deficit drought is caused exclusively by a prolonged lack of rainfall (meteorological drought) that propagates through the hydrological cycle and develops into a hydrological drought.

Some examples are shown in Fig. 5 with droughts in summer, spring, and winter in different catchments. In the first example (Fig. 5a, Narsjø catchment), a meteorological drought in May-July 1992 (3rd panel) caused drought in soil moisture, groundwater storage, and discharge (4th, 5th, and 6th panel). The hydrological drought event ended by high precipitation in July-August 1992 (3rd panel). In the second example (Fig. 5b, Nedožery catchment), a meteorological 

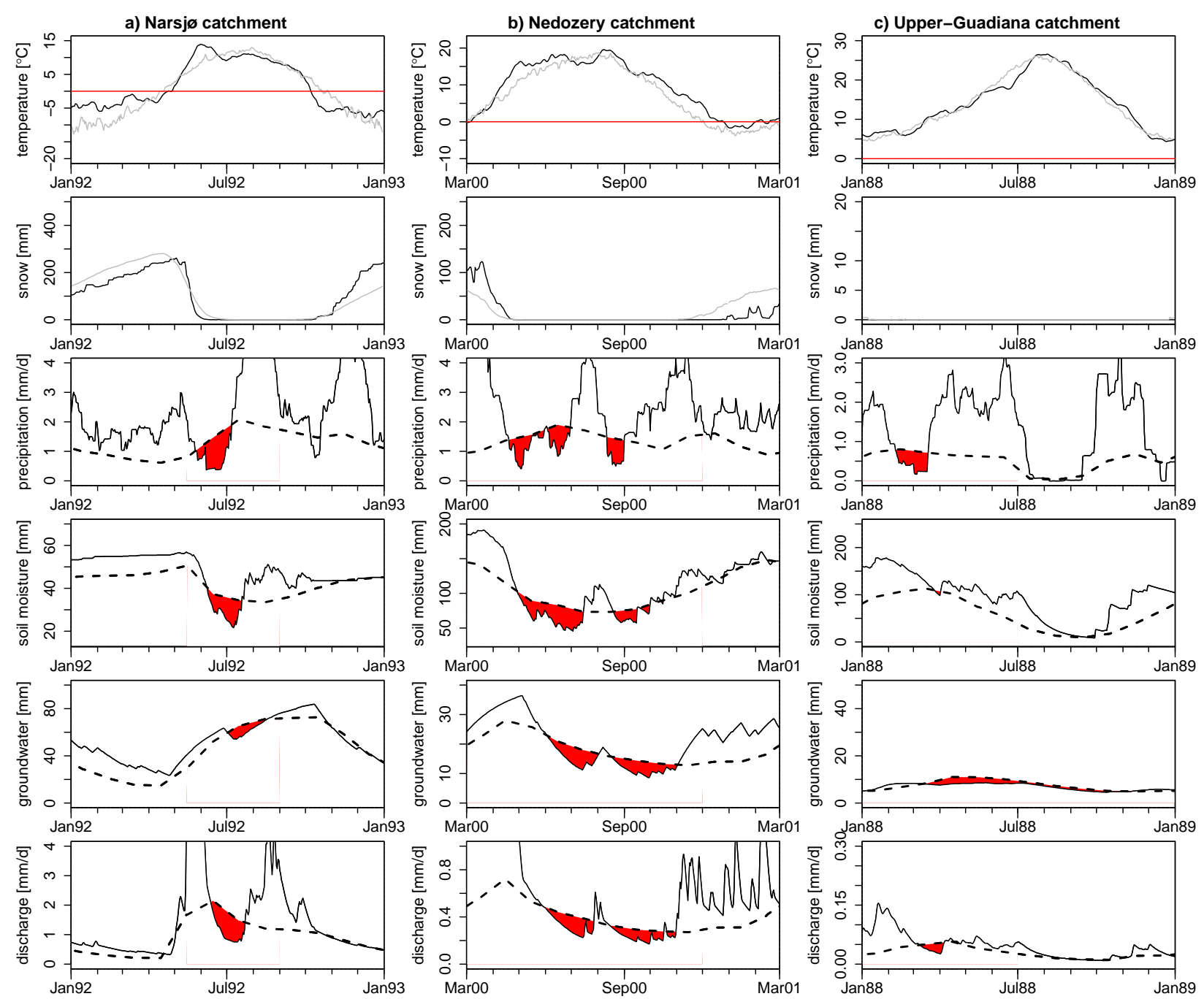

Fig. 5. Examples of classical rainfall deficit drought type: (a) Narsjø catchment 1992-1993, (b) Nedožery catchment 2000-2001, (c) UpperGuadiana catchment 1988 (all panels: grey line = long-term average of displayed variable, dashed line = smoothed monthly $80 \%$-threshold of displayed variable, red area $=$ drought event referred to in text; upper panel: black line $=30$-day moving average of observed temperature, red line $=0$ degrees; second panel: black line = simulated snow accumulation; third panel: black line $=30$-day moving average of observed precipitation; fourth panel: black line = simulated soil moisture; fifth panel: black line = simulated groundwater storage; lower panel: black line $=$ simulated discharge).

drought in April-June 2000 and one in August 2000 (3rd panel) both caused a soil moisture drought (4th panel) and a hydrological drought (groundwater storage and discharge; 5th and 6th panel), with a small peak in between due to rainfall in July 2000 (3rd panel). The hydrological drought event ended by high precipitation in autumn (SeptemberNovember 2000; 3rd panel). In the third example (Fig. 5c, Upper-Guadiana catchment), a meteorological drought in winter (February-March 1988; 3rd panel) caused only a minor drought in soil moisture (4th panel) and a hydrological drought (groundwater storage and discharge; starting in March 1988; 5th and 6th panel). The drought in soil moisture and discharge ended by rainfall in spring (March-June 1988; 3rd panel), but the drought in groundwater storage continued because recharge was not sufficient (5th panel).
The classical rainfall deficit drought can occur in any season, in any catchment (quickly or slowly responding), and in any climate region (Köppen-Geiger climate types A, B, $\mathrm{C}, \mathrm{D}$, and $\mathrm{E}$ ), as long as precipitation falls as rain (snow related droughts are treated in Sects. 4.2, 4.4 and 4.5). A classical rainfall deficit drought can have all possible durations, deficit volumes, and maximum deviations, mainly dependent on the rainfall deficit(s) that caused it and on the antecedent storage in the catchment. In the examples in Fig. 5, durations range from 28 to 245 days, maximum deviations from 2.9 to $10.7 \mathrm{~mm}$, and deficit volumes from 0.45 to $28 \mathrm{~mm}$. Classical rainfall deficit droughts can show all propagation features (i.e. pooling, lag, attenuation, and lengthening; see Sect. 1), mainly dependent on catchment characteristics. Pooling, for example, often occurs. The examples in Fig. 5 show a clear 
propagation of one meteorological drought into one hydrological drought, but in many cases more meteorological droughts are pooled and it is harder to point out the exact rainfall deficits that caused a specific hydrological drought. In the examples in Fig. 5, lag (groundwater: 9-44 days, discharge: 7-39 days) and attenuation of the drought signal are visible in all catchments, and lengthening of the drought period is striking in the Nedožery catchment (Fig. 5b) and especially in the groundwater storage of the Upper-Guadiana catchment (Fig. 5c).

The classical rainfall deficit drought is a very common hydrological drought type. As it occurs all around the world, it has been described and analysed by many different authors. Some examples are Stahl and Demuth (1999); Tallaksen and Van Lanen (2004); Stahl and Hisdal (2004); Smakhtin and Hughes (2004); and Fleig et al. (2006).

\subsection{Rain-to-snow-season drought}

The rain-to-snow-season drought is caused by a rainfall deficit (meteorological drought) in the rain season (usually summer and/or autumn) that continues into the snow season (usually winter). The meteorological drought ends with precipitation, which, however, falls as snow because temperature has dropped below zero. Consequently, soil moisture and groundwater stores are not replenished by recharge in the rain season, the season in which recharge normally takes place. Therefore, the initial value of the normal winter recession is lower than normal and groundwater storage and discharge stay below the threshold level until the snow melt peak of the next spring.

Two examples of the rain-to-snow-season drought are shown in Fig. 6. In the first example (Fig. 6a, Narsjø catchment), the meteorological drought in July, August and September 1968 (3rd panel) directly resulted in a soil moisture drought (4th panel) and hydrological drought (5th and 6th panel). The precipitation peak that started mid-October (3rd panel) mainly fell as snow (2nd panel) because temperatures had dropped below zero (1st panel). Some replenishment of the soil moisture store took place and the soil moisture drought disappeared (4th panel), but the groundwater system remained in drought until the snow melt peak of May 1969 (5th panel). In the second example (Fig. 6b, Upper-Sázava catchment), two meteorological droughts of July and September-October 1969 (3rd panel) caused groundwater storage (5th panel) and discharge (6th panel) to decrease below threshold levels. Part of the precipitation of November 1969 and almost all that of February 1970 (3rd panel) fell as snow (1st and 2nd panel). Therefore, the hydrological drought did not end, but continued until the snow melt period of April 1970 (6th panel). In the groundwater system, the drought even continued longer, until July 1970 (not shown).
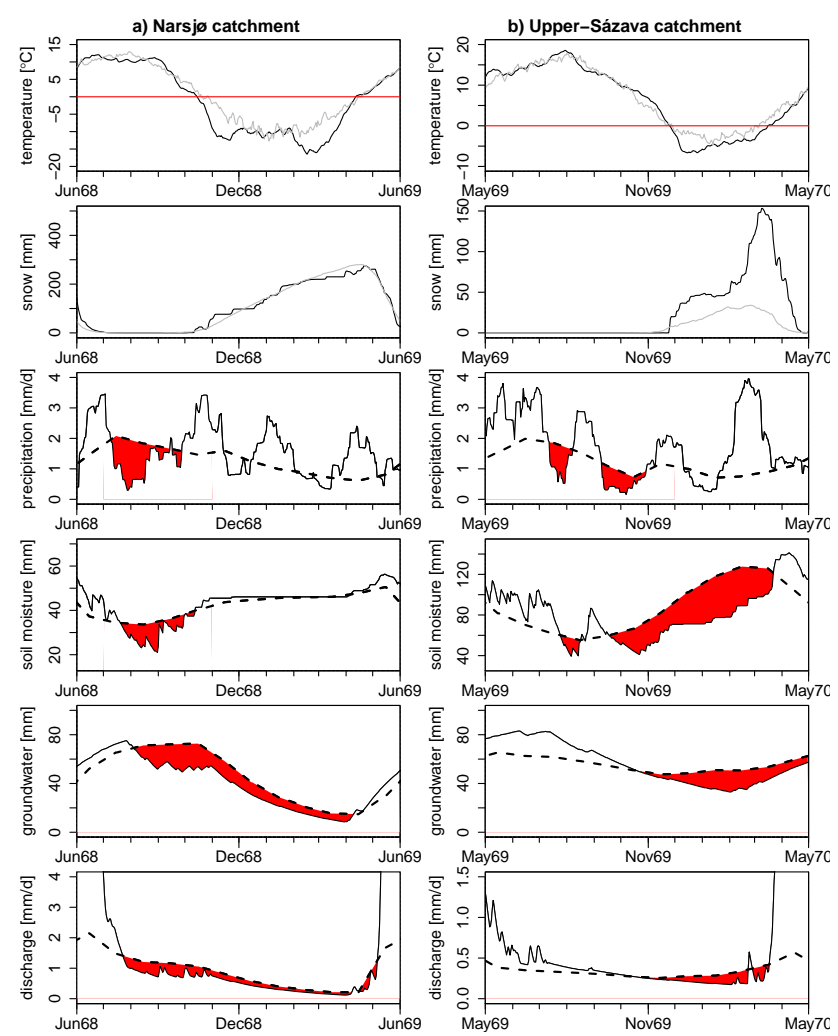

Fig. 6. Examples of rain-to-snow-season drought type: (a) Narsjø catchment 1968-1969, (b) Upper-Sázava catchment 1969-1970 (legend: see Fig. 5).

The rain-to-snow-season drought occurs in catchments with a clear snow season, which can be catchments at high latitude or high elevation (Köppen-Geiger climate types D and $\mathrm{E}$, and some subtypes of $\mathrm{C}$ ). These catchments have a low-flow season in winter due to the continuous snow cover that hampers recharge. Durations of rain-to-snow-season droughts are long (almost up to a year; in the examples of Fig. 6, 279 and 147 days for drought in discharge) and deficit volumes can be high (partly due to the long durations; in the examples of Fig. 6, 54 and $11 \mathrm{~mm}$ for drought in discharge). As can be seen from the examples in Fig. 6, lengthening is the main drought propagation feature defining rain-to-snowseason droughts. Other drought propagation features also occur (e.g. pooling and lag in Fig. 6b), but are less important than lengthening.

The rain-to-snow-season drought has previously been described by Van Loon et al. (2010) under the name Type 1 winter drought. Pfister et al. (2006) mention historical evidence of a hydrological winter drought event in 1540 that might have been of this type. In other studies, these multiseason droughts are mostly filtered out, because they complicate statistical analysis (Hisdal et al., 2001; Fleig et al., 2006). 


\subsection{Wet-to-dry-season drought}

The wet-to-dry-season drought is governed by the same principle as the rain-to-snow-season drought, only in this case no snow is involved, but a very high potential evaporation in the dry season. The wet-to-dry-season drought is caused by a rainfall deficit (meteorological drought) in the wet season (usually winter) that continues into the dry season (usually summer). The meteorological drought ends with precipitation, which, however, is completely lost to evapotranspiration because potential evaporation in this season is higher than precipitation. Consequently, soil moisture and groundwater stores are not replenished by recharge in the wet season, the season in which recharge normally takes place. Therefore, the initial value of the normal summer recession is lower than normal and groundwater storage and discharge stay below the threshold level until the next wet season.

Two examples of the wet-to-dry-season drought are shown in Fig. 7 (both Upper-Guadiana catchment; in the other studied catchments the potential evaporation is not sufficiently high to cause this type of drought). In the first example (Fig. 7a), one large meteorological drought in the wet season (April-June 1987; 3rd panel) caused discharge to drop below the threshold level (6th panel). Groundwater was already in drought (5th panel) as remnant of a previous dry period. The rainfall event of June-July 1987 (3rd panel) did not result in recovery from the hydrological drought, because it was partly lost to evapotranspiration and partly used for replenishment of soil moisture (4th panel). The hydrological drought continued until December 1987 (6th panel), when rainfall was high (3rd panel) and potential evaporation lower than in summer. In the second example (Fig. 7b), a number of small meteorological drought events in the wet season (between November 1998 and May 1999; 3rd panel) resulted in a soil moisture drought in the wet season (4th panel) and a decrease in groundwater storage and discharge to belowthreshold levels (5th and 6th panel). In both examples, the hydrological drought continued throughout the dry season, until the first recharge in the following wet season (NovemberDecember).

The wet-to-dry-season drought occurs in catchments with a clear wet and dry season (Köppen-Geiger climate subtypes A-monsoon climate, B-steppe climate, and C-Mediterranean climate). Durations are long (half a year to a year; in the examples of Fig. 7, 222 and 243 days for drought in discharge), and deficit volumes can be high in wet climates and often stay low in semi-arid climates because of the low threshold level (in the examples of Fig. 7, 3.0 and $2.7 \mathrm{~mm}$ for drought in discharge). Just as rain-to-snow-season droughts, lengthening is the main drought propagation feature defining wetto-dry-season droughts. Other drought propagation features also occur (e.g. pooling and lag in Fig. 7b), but are less important than lengthening.

The wet-to-dry-season drought has previously been described by Tate and Freeman (2000); Van Lanen et al. (2004);
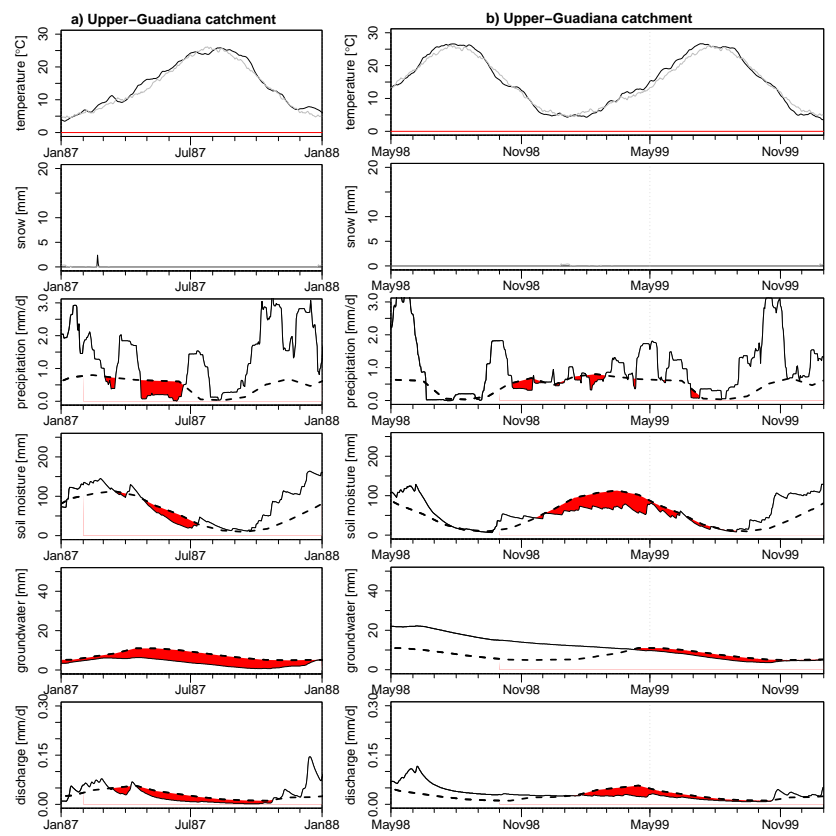

Fig. 7. Examples of wet-to-dry-season drought type: (a) UpperGuadiana catchment 1987, (b) Upper-Guadiana catchment 19981999 (legend: see Fig. 5).

Stahl and Hisdal (2004); Trigo et al. (2006); Santos et al. (2007); Pandey et al. (2008); Trigo et al. (2010); and Kim et al. (2011).

\subsection{Cold snow season drought}

The cold snow season drought is caused by an abnormally low temperature in the snow season (winter), possibly, but not necessarily, in combination with a meteorological drought in that same season. Three subtypes are distinguished, subtype A and B in cold climates and subtype $\mathrm{C}$ in temperate climates.

Subtype A - in climates with temperatures well below zero and a continuous snow cover in winter (Köppen-Geiger climate types $\mathrm{D}$ and $\mathrm{E}$ ), a below-normal winter temperature only influences the beginning and end of the snow season. If temperatures are low during the beginning of winter, temperatures drop below zero earlier in the year than normal and precipitation falls earlier as snow. This causes the normal winter recession period to start earlier than normal. When the initial values of the recession of soil moisture, groundwater storage, and discharge are high enough, this will not lead to drought (see Sect. 5.3); but when storage and discharge are already low, groundwater storage and discharge can go below threshold levels during winter. An example is shown in Fig. 8a (Narsjø catchment). In this case, temperature decreased below zero two weeks early, in the beginning of October instead of the end of October 1960 (1st panel), and the precipitation of October fell as snow (2nd and 3rd panel). The recession of groundwater storage and discharge 

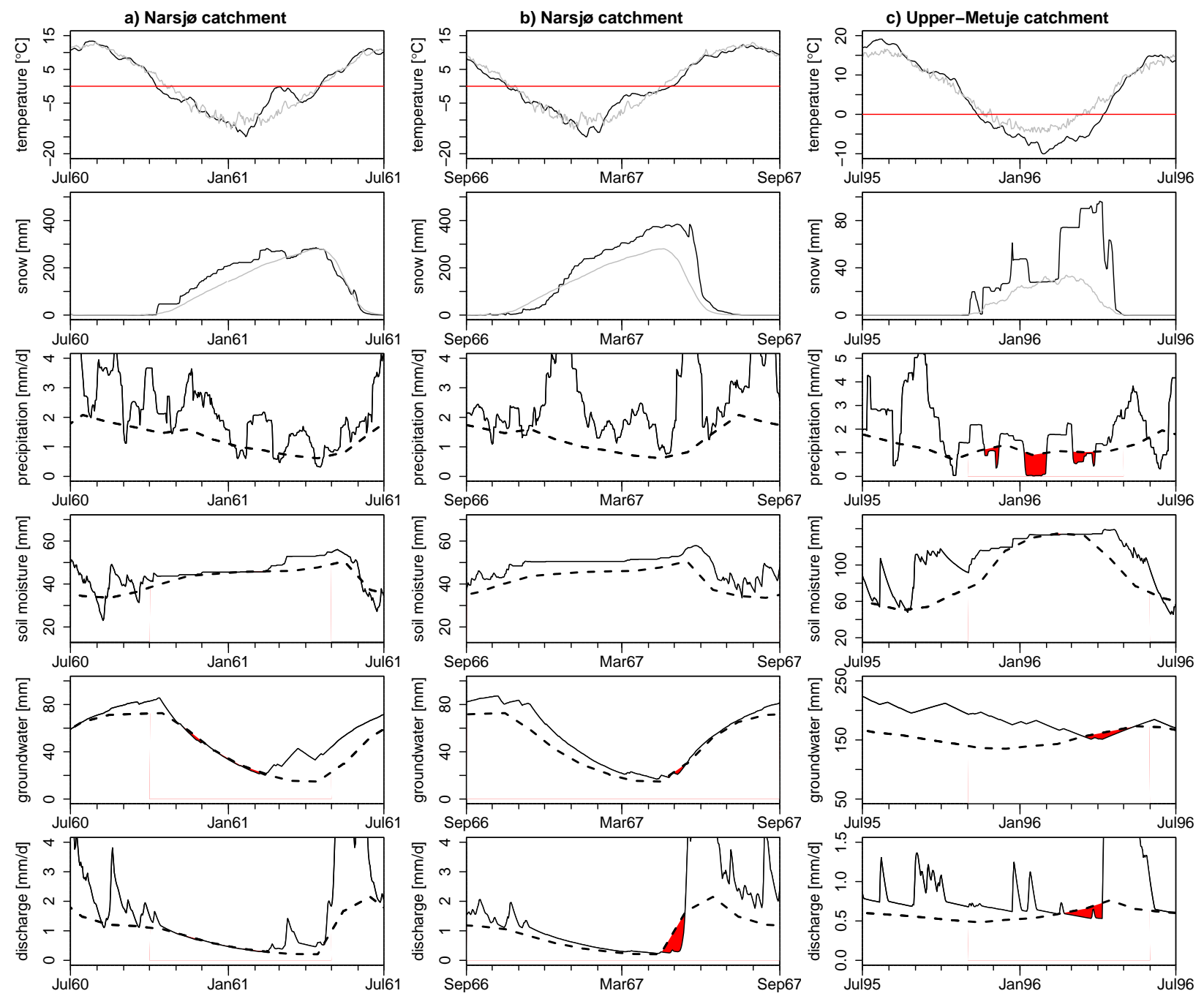

Fig. 8. Examples of cold snow season drought type: (a) Narsjø catchment 1960-1961, (b) Narsjø catchment 1966-1967, (c) Upper-Metuje catchment 1995-1996 (legend: see Fig. 5).

started earlier than normal and the values dropped just below threshold level from November 1960 to February 1961 (5th and 6th panel). The hydrological drought ended by some snow melt in March 1961, caused by high temperatures (1st panel). Cold snow season droughts-subtype A usually have a long duration (several months), but a low deficit volume and small maximum deviation because groundwater storage and discharge are just below the threshold level. In the example in Fig. 8a, durations are 83 and 93 days for groundwater storage and discharge, respectively, and deficit volume of discharge is only $1.6 \mathrm{~mm}$. Drought propagation features are not applicable, because this type of hydrological drought is not caused by a meteorological drought $(P$-control), but only by a temperature anomaly ( $T$-control).

Subtype B - if, in the same cold climates, temperatures are low at the end of winter, snow melt is later than normal. A late snow melt leads to below-threshold levels when groundwater storage and discharge stay low while threshold levels increase. An example is shown in Fig. 8b (Narsjø catchment). In this case, temperature stayed below zero until the beginning of May instead of mid-April (three weeks later than normal; 1st panel) and snow melt was delayed (2nd panel). Threshold levels started to increase by midApril, while groundwater storage and discharge still showed a recession (5th and 6th panel). When temperature finally increased above zero in the beginning of May (1st panel), snow melt (2nd panel) ended the hydrological drought (5th and 6th panel). Cold snow season droughts-subtype B can have high deficit volumes (in the example $15.2 \mathrm{~mm}$ ), but only short durations, in the order of a few weeks (in the example about three weeks). This type of drought is mostly confined to discharge and is usually not found in groundwater. Again, drought propagation features are not applicable. This specific case of cold snow season drought should not be confused 
with a snow melt anomaly, which does not have an abnormal temperature pattern, but is only caused by the very sharp increase in discharge in combination with a gradually rising threshold level (see Sect. 3.2.1).

Subtype $\mathrm{C}$ - in climates with temperatures around zero and some snow accumulation in winter (Köppen-Geiger climate types $\mathrm{C}$ and some subtypes of $\mathrm{D}$ ), the effect is different. In these climates, the snow season normally provides recharge to the groundwater system, due to occasional and partial melt of the snow cover. So, the normal winter situation is one of increasing storage and discharge. If, however, winter temperatures decrease to values well below zero and no melting of snow takes place, recharge decreases to zero. If low temperatures persist, a hydrological drought can develop. This is clearly visible in Fig. 8c (Upper-Metuje catchment). In December 1995 to April 1996 temperatures were lower than normal (on average $-3.9^{\circ} \mathrm{C}$ instead of $-0.4{ }^{\circ} \mathrm{C}$; 1st panel) and snow accumulation was higher than normal (2nd panel). The lack of recharge caused a decrease in groundwater storage and discharge, leading mid-February to drought in discharge (6th panel) and mid-March to drought in groundwater (5th panel). The drought ended by snow melt. A cold snow season drought-subtype $\mathrm{C}$ typically has a duration of a few weeks to months (in this example 60 days in groundwater and 47 days in discharge) and an intermediate deficit volume (in this example $4.4 \mathrm{~mm}$ ). Again, drought propagation features are not applicable, although the reaction of groundwater can be different from that of discharge (delayed and attenuated, like in Fig. 8c).

Stahl and Demuth (1999) and Pfister et al. (2006) mention a cold winter as a reason for drought, but do not describe underlying processes. Van Lanen et al. (2004) discuss causative mechanisms of various cold snow season droughts.

\subsection{Warm snow season drought}

The warm snow season drought is caused by an abnormally high temperature in the snow season (winter), in some cases in combination with a rainfall deficit (meteorological drought) in that same season. Two subtypes are distinguished, subtype A in cold climates and subtype B in temperate climates.

Subtype A - in climates with temperatures well below zero and a continuous snow cover in winter (Köppen-Geiger climate types D and E), a higher winter temperature, again, only influences the beginning and end of the snow season. If temperatures are high during the beginning of winter, more precipitation will fall as rain instead of snow and a drought in the snow season will be less likely (see Sect. 5.3). However, if temperatures are high at the end of winter, snow melt is earlier than normal. An early snow melt leads to an early peak in discharge, resulting in lower discharge values in the following normal snow melt period. Discharge can drop below the (high) threshold level. If a rainfall deficit occurs in the spring season, it can aggravate this warm snow season drought.
In the example in Fig. 9a (Narsjø catchment), temperature increased to above zero three weeks early, at the end of March 2004 instead of mid-April (1st panel), resulting in an early snow melt (2nd panel). Consequently, the peak in discharge (normally in June) was advanced to April-May and in June a hydrological drought developed (6th panel), because threshold levels were high and discharge already decreased after the snow melt peak. So, a warm snow season droughtsubtype A can develop without a meteorological drought (although precipitation was not extremely high in May 2004; Fig. 9a). The reason is the normally-occurring pronounced snow melt peak in cold climates that is clearly reflected in the threshold level. Warm snow season droughts-subtype A usually have short durations (in the example in Fig. 9a, 25 days). Deficit volumes can be high (in the example $8.2 \mathrm{~mm}$ ) due to the high threshold level. A warm snow season droughtsubtype A is mostly confined to discharge and is usually not found in groundwater. Again, drought propagation features are not applicable, because this type of hydrological drought is not caused by a meteorological drought ( $P$-control) but by a temperature anomaly ( $T$-control).

Subtype B - in climates with temperatures around zero and some snow accumulation in winter (Köppen-Geiger climate types $\mathrm{C}$ and some subtypes of $\mathrm{D}$ ), the effect is different. In these climates the snow season normally provides recharge to the groundwater system, due to occasional and partial melt of the snow cover. If, however, winter temperatures rise above zero and the snow cover melts completely, no snow store is left that can provide recharge. If, at the same time, a meteorological drought occurs, a hydrological drought can develop. Two examples of this case of the warm snow season drought are shown in Fig. 9. In the first example (Fig. 9b, Upper-Sázava catchment), the warm and dry period of February-March 1974 (1st and 3rd panel) caused a complete melt of the snow cover (2nd panel) and afterwards a lack of recharge to groundwater. Consequently, a hydrological drought developed (5th and 6th panel) that continued until the high rainfall period in the spring of 1974 (3rd panel). In the second example (Fig. 9c, Nedožery catchment), the high temperatures of December 1989 to March 1990 (1st panel) also led to a complete melt of the snow cover (2nd panel). The meteorological drought of December 1989January 1990 (3rd panel) therefore triggered a soil moisture (4th panel) and hydrological drought (5th and 6th panel). The rainfall peak in March 1990 (3rd panel) caused a quick reaction in discharge (6th panel), but did not end the drought that continued until May-June 1990. That spring, no snow melt peak occurred because the snow cover had already melted in December (2nd panel). So, contrary to the rain-to-snowseason drought, the cold snow season drought-subtypes A$\mathrm{C}$, and the warm snow season drought-subtype A that are also winter droughts (Sects. 4.2, 4.4, and 4.5), the warm snow season drought-subtype B is not ended by a snow melt peak, because snow cover already melted before. A warm snow season drought-subtype B can continue into summer. 

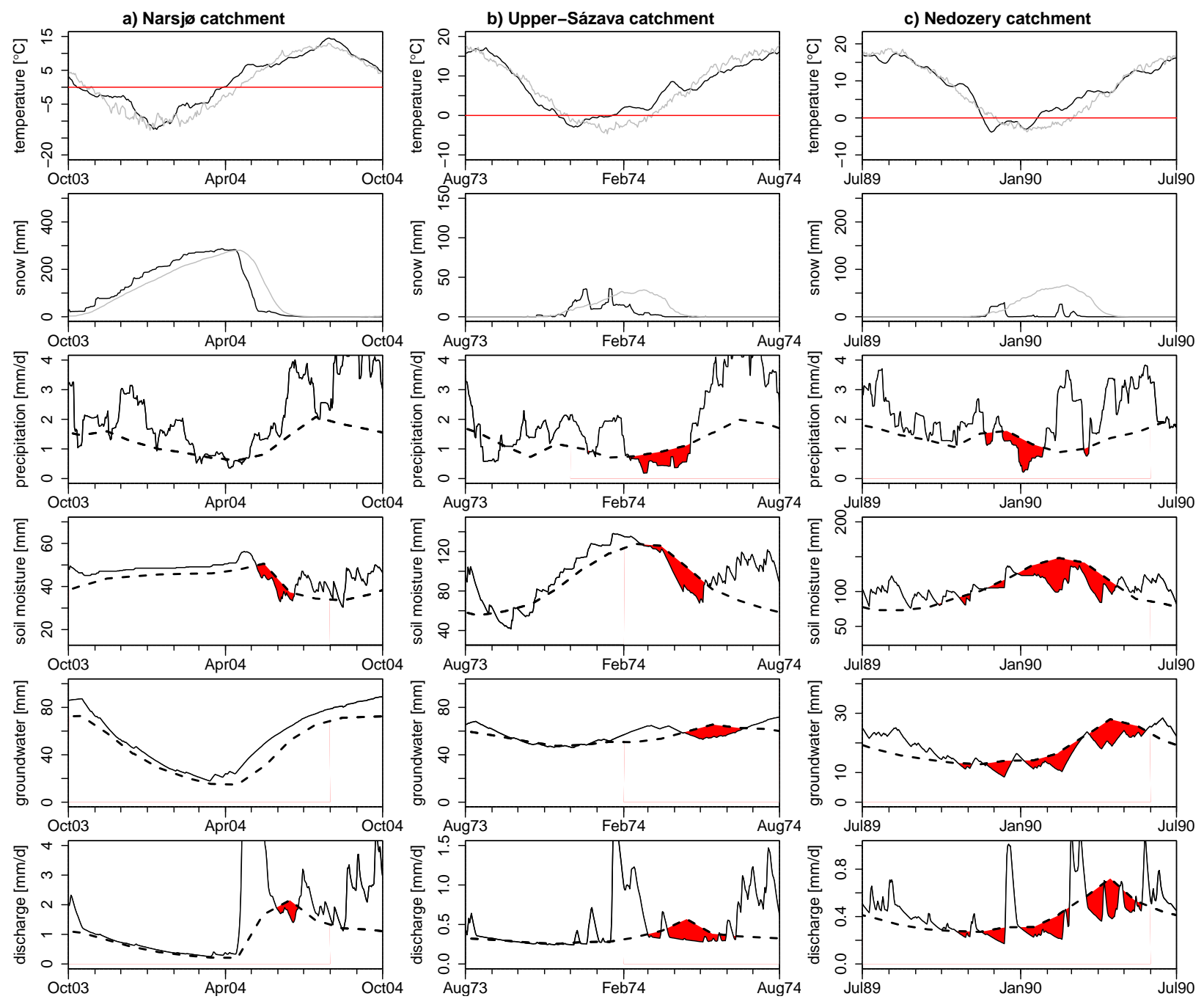

Fig. 9. Examples of warm snow season drought type: (a) Narsjø catchment 2003-2004, (b) Upper-Sázava catchment 1973-1974, (c) Nedožery catchment 1989-1990 (legend: see Fig. 5).

Durations can be long and deficit volumes high. Warm snow season droughts-subtype B can show all propagation features (i.e. pooling, lag, attenuation, and lengthening; see Sect. 1), mainly dependent on catchment characteristics.

The warm snow season drought-subtype A has previously been described by Van Lanen et al. (2004), and subtype B by Van Loon et al. (2010) under the name Type 2 winter drought.

\subsection{Composite drought}

A composite drought combines a number of drought generating mechanisms. In this hydrological drought type, a number of drought events (of the same or different type) in distinct seasons cannot be distinguished any more. The main feature of the composite drought is that the system has not recovered from a hydrological drought event, when the next event starts.
Examples of the composite drought are shown in Fig. 10. The first example (Fig. 10a, Upper-Metuje catchment) shows two classical rainfall deficit droughts in subsequent summers (1982 and 1983, 3rd panel) that are combined into one hydrological drought (5th and 6th panel). The drought in groundwater started in July 1983 and lasted for 440 days. The drought in discharge was interrupted by some small rainfall peaks in December 1982 and January 1983, and a snow melt peak in April 1983, but every time it returned to below-threshold levels afterwards. In total, the drought in discharge had a net duration of 330 days and a deficit volume of $22.2 \mathrm{~mm}$. The hydrological drought ended by high precipitation events by the end of 1984 . In the second example (Fig. 10b, Upper-Sázava catchment), the hydrological drought that lasted from December 1989 to August 1991 (5th and 6th panel) was caused by two warm snow season droughts-subtype B in the winter of 1989-1990 

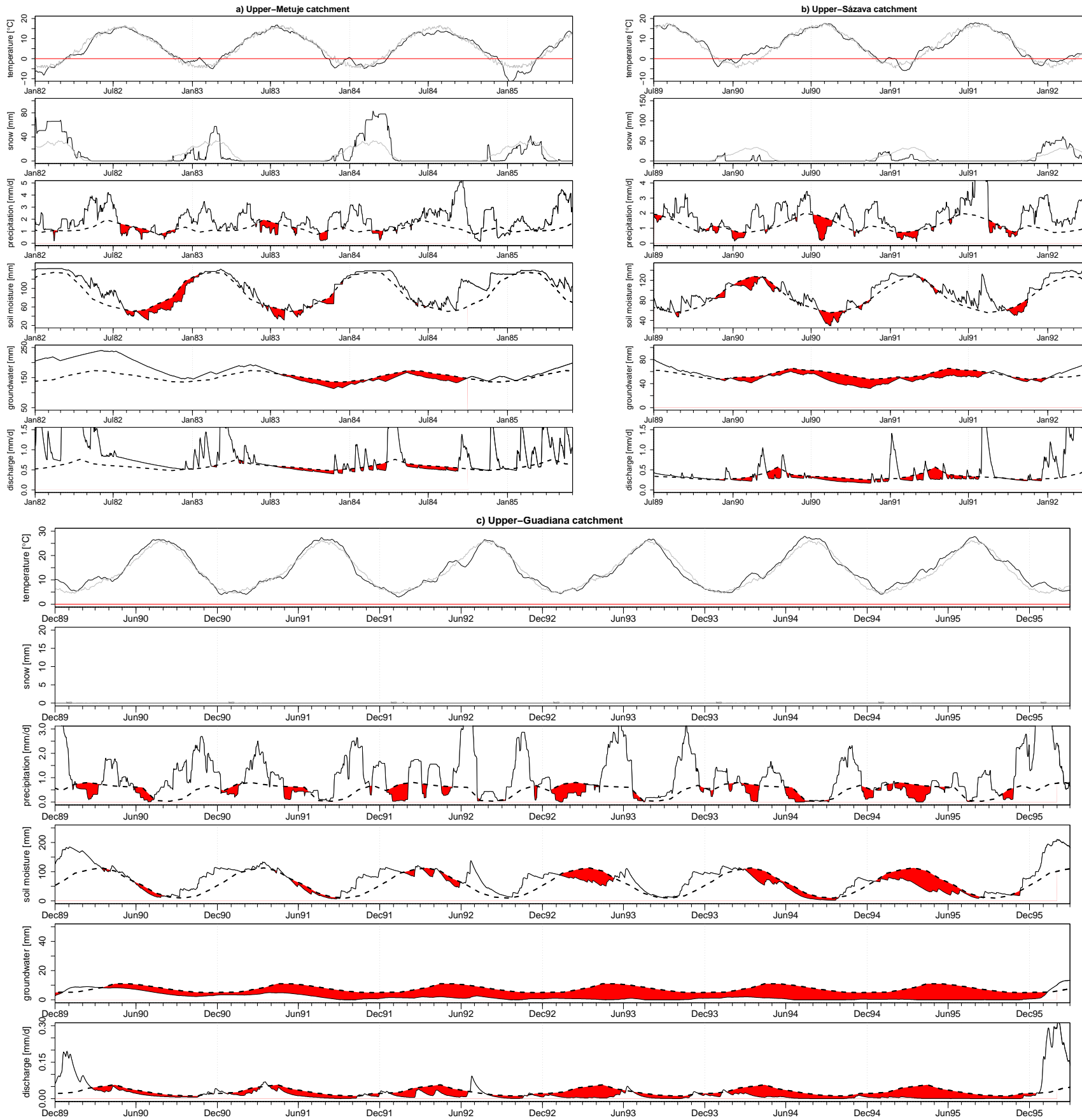

Fig. 10. Examples of composite drought type: (a) Upper-Metuje catchment 1982-1985, (b) Upper-Sázava catchment 1989-1992, (c) UpperGuadiana catchment 1989-1995 (legend: see Fig. 5).

and 1990-1991 (1st, 2nd and 3rd panel) and a classical rainfall deficit drought in the summer of 1990 (3rd panel). The precipitation peaks in between caused small discharge peaks that interrupted the hydrological drought, but afterwards discharge returned to its low level. In the third example (Fig. 10c, Upper-Guadiana catchment), a large number of classical rainfall deficit droughts (3rd panel) and wet-to-dry-season droughts (3rd and 4th panel) in subsequent years are combined into a very long hydrological drought (5th and 6th panel). The drought in groundwater lasted for 2126 days (March 1990 until January 1995). In discharge, a number of separate drought events can still be distinguished, for example a wet-to-dry-season drought from 
February to October 1990, and a classical rainfall deficit drought from December 1990 to March 1991.

Composite droughts only occur in catchments with a long memory, so catchments with considerable storage. This storage can be in e.g. aquifers, bogs, lakes. Composite droughts can occur in all climates, but are most likely in (semi-)arid climates (Köppen-Geiger climate type B) due to the irregular rainfall pattern in these climates. The drought types that are combined differ per catchment and climate zone. Composite droughts have long to very long durations (often multi-year) and deficit volumes are high (for the examples in Fig. 10, 20-40 mm in total). The main drought propagation feature defining composite droughts is pooling, and this type of drought is especially pronounced in groundwater and less in discharge.

The composite drought has previously been mentioned by Bierkens and van den Hurk (2007) and Marsh et al. (2007), and analysed by Van Loon et al. (2011a) under the name Multi-year drought.

\section{Application of the hydrological drought typology in the study catchments}

As an example of the application of the hydrological drought typology, we classified drought events in the study catchments (Sect. 2). Knowledge on the occurrence of drought types in a catchment is valuable information for water managers. In water management, not only knowing the typology of all drought events is useful, but especially the typology of the most severe events and also the development of non-drought events (the situations where a meteorological drought did not result in a hydrological drought).

\subsection{Typology of all drought events}

Some of the hydrological drought types defined in Sect. 4 occurred in all catchments, others only in one or two of the studied catchments. That is because some hydrological drought types are specific for a certain climate type (e.g. rainto-snow-season drought and wet-to-dry-season drought) or for a certain catchment type (e.g. composite drought). Table 4 shows that the classical rainfall deficit drought occurred in all studied catchments and the wet-to-dry-season drought only in one (Upper-Guadiana). The other drought types occurred in more than one of the studied catchments, but in different percentages.

Drought events in groundwater and discharge showed a comparable distribution over the drought types (Table 4). Droughts in discharge only showed up in more categories than droughts in groundwater, because the total number of droughts in discharge was higher (Table 3), resulting in higher possibility for different drought types. In groundwater, these drought events have grown together and formed a composite drought. Consequently, the percentage of

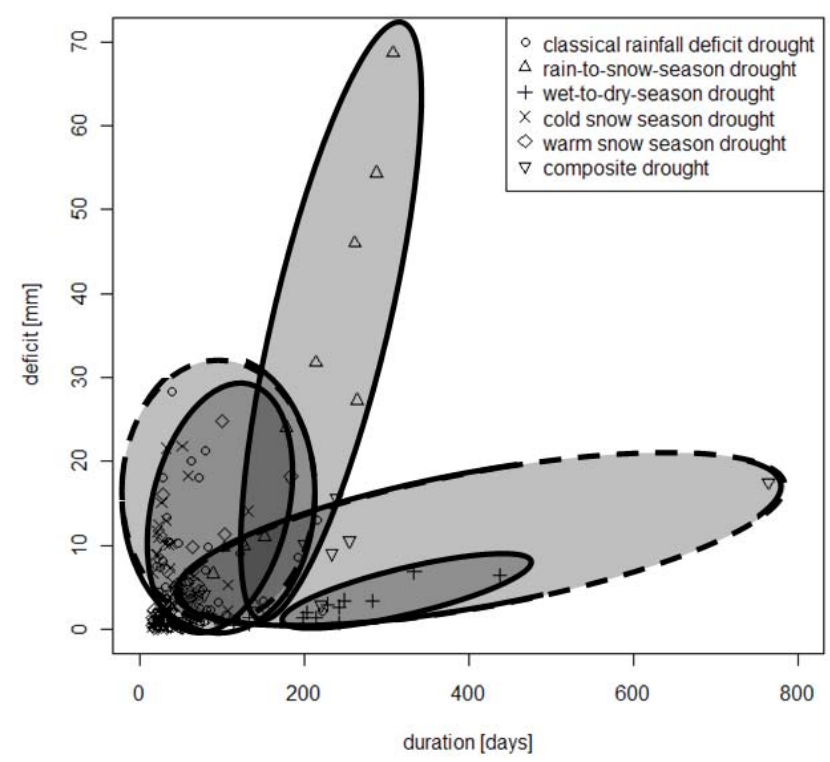

Fig. 11. Drought duration and deficit volume of all discharge drought events grouped per hydrological drought type (ellipses are added to more clearly identify groups of events with similar drought type; dashed lines indicate an approximation based on a single event).

composite droughts in groundwater was, in general, higher than that of discharge (Table 4; exception Upper-Sázava). Furthermore, warm snow season droughts were more clearly visible in discharge than in groundwater, because these droughts are easily attenuated in the stores.

The classical rainfall deficit drought occurred in all studied catchments with percentages often around $50 \%$ (Table 4). This is the most common hydrological drought type in these catchments. Only in the groundwater drought events of the Upper-Guadiana catchment, the classical rainfall deficit drought was not recognisable any more because it was included in composite droughts.

The rain-to-snow-season drought occurred only in catchments with a clear snow season, i.e. Narsjø, Upper-Metuje, Upper-Sázava, and Nedožery. Percentages are relatively low (7 to $19 \%$; Table 4 ).

The wet-to-dry-season drought occurred only in UpperGuadiana, because that is the only studied catchment with a clear dry season in which potential evaporation exceeds precipitation (Cs and Bs climate types; Table 1).

The cold snow season drought occurred in all studied catchments, but with varying percentages. The $3 \%$ of the Upper-Guadiana catchment reflect only one event in the time series of $42 \mathrm{yr}$. This was an extremely cold winter (19701971) with considerable snow accumulation. The large number of cold snow season droughts in the Narsjø catchment are caused by an early start of the snow season (subtype A) or a late end (subtype B). The cold snow season droughts in Upper-Metuje, Upper-Sázava, and Nedožery catchments are 
Table 4. Drought types of all drought events per catchment (groundwater and discharge).

\begin{tabular}{|c|c|c|c|c|c|c|c|}
\hline & & $\begin{array}{r}\text { Classical rainfall } \\
\text { deficit drought }\end{array}$ & $\begin{array}{l}\text { Rain-to-snow- } \\
\text { season drought }\end{array}$ & $\begin{array}{l}\text { Wet-to-dry- } \\
\text { season drought }\end{array}$ & $\begin{array}{r}\text { Cold snow } \\
\text { season drought }\end{array}$ & $\begin{array}{r}\text { Warm snow } \\
\text { season drought }\end{array}$ & $\begin{array}{r}\text { Composite } \\
\text { drought }\end{array}$ \\
\hline \multirow[t]{2}{*}{ Narsjø } & groundwater & $28 \%$ & $13 \%$ & - & $54 \%$ & - & - \\
\hline & discharge & $32 \%$ & $10 \%$ & - & $47 \%$ & $5 \%$ & - \\
\hline \multirow[t]{2}{*}{ Upper-Metuje } & groundwater & $50 \%$ & $19 \%$ & - & $13 \%$ & - & $19 \%$ \\
\hline & discharge & $52 \%$ & $7 \%$ & - & $15 \%$ & $19 \%$ & $7 \%$ \\
\hline \multirow[t]{2}{*}{ Upper-Sázava } & groundwater & $58 \%$ & $11 \%$ & - & $11 \%$ & $11 \%$ & $11 \%$ \\
\hline & discharge & $36 \%$ & $2 \%$ & - & $21 \%$ & $24 \%$ & $14 \%$ \\
\hline \multirow[t]{2}{*}{ Nedožery } & groundwater & $57 \%$ & $8 \%$ & - & $14 \%$ & $22 \%$ & - \\
\hline & discharge & $53 \%$ & $9 \%$ & - & $14 \%$ & $23 \%$ & - \\
\hline \multirow[t]{2}{*}{ Upper-Guadiana } & groundwater & - & - & $33 \%$ & - & - & $67 \%$ \\
\hline & discharge & $50 \%$ & - & $35 \%$ & $3 \%$ & - & $5 \%$ \\
\hline
\end{tabular}

Table 5. Drought types of 5 most severe drought events per catchment (groundwater and discharge).

\begin{tabular}{|c|c|c|c|c|c|c|c|}
\hline & & $\begin{array}{r}\text { Classical rainfall } \\
\text { deficit drought }\end{array}$ & $\begin{array}{l}\text { Rain-to-snow- } \\
\text { season drought }\end{array}$ & $\begin{array}{l}\text { Wet-to-dry- } \\
\text { season drought }\end{array}$ & $\begin{array}{r}\text { Cold snow } \\
\text { season drought }\end{array}$ & $\begin{array}{r}\text { Warm snow } \\
\text { season drought }\end{array}$ & $\begin{array}{r}\text { Composite } \\
\text { drought }\end{array}$ \\
\hline \multirow[t]{2}{*}{ Narsjø } & groundwater & $20 \%$ & $80 \%$ & - & - & - & - \\
\hline & discharge & $20 \%$ & $80 \%$ & - & - & - & - \\
\hline \multirow[t]{2}{*}{ Upper-Metuje } & groundwater & $20 \%$ & $40 \%$ & - & - & - & $40 \%$ \\
\hline & discharge & $60 \%$ & $20 \%$ & - & - & - & $20 \%$ \\
\hline \multirow[t]{2}{*}{ Upper-Sázava } & groundwater & $20 \%$ & $40 \%$ & - & - & - & $40 \%$ \\
\hline & discharge & $20 \%$ & $20 \%$ & - & - & $40 \%$ & $20 \%$ \\
\hline \multirow[t]{2}{*}{ Nedožery } & groundwater & - & $20 \%$ & - & $40 \%$ & $40 \%$ & - \\
\hline & discharge & $40 \%$ & $20 \%$ & - & - & $40 \%$ & - \\
\hline \multirow[t]{2}{*}{ Upper-Guadiana } & groundwater & - & - & - & - & - & $100 \%$ \\
\hline & discharge & $20 \%$ & - & $40 \%$ & - & - & $20 \%$ \\
\hline
\end{tabular}

mostly due to a lack of recharge in winter (subtype C) and sometimes due to a late end of the snow season (subtype B).

The warm snow season drought is not represented in the Upper-Guadiana catchment, because of its warm climate. In the Narsjø catchment, some warm snow season droughtsubtype A occurred, but only in discharge. In the catchments with temperatures around or just below zero in winter (i.e. Upper-Metuje, Upper-Sázava, Nedožery), most warm snow season droughts were found (around $20 \%$ occurrence). These were all subtype B droughts.

The composite drought occurred in slowly responding catchments, with the highest percentage in Upper-Guadiana (67\% for groundwater droughts) and lower percentages in Upper-Metuje and Upper-Sázava (7 to 19\%). UpperGuadiana had very long droughts that span over different seasons and even years (Table 3 ) due to the long memory in its extensive groundwater system.

A few events are not included in Table 4 (causing percentages of some catchments not to add up to $100 \%$ ). In the Narsjø catchment, these omitted events are classified as anomalies (and thus disregarded, see Sect. 3.2.1) and in the Upper-Guadiana catchment, a few events were unidentifiable, because they were a remnant drought from low storage in groundwater that did not have a clear cause in precipitation or temperature. In these events, discharge returned to a drought situation after a small peak caused by a rainfall event.

If drought characteristics of all discharge drought events in the five studied catchments are grouped by drought type (Fig. 11), some drought types stand out. Especially rain-to-snow-season droughts, wet-to-dry-season droughts, and composite droughts show a distinct pattern with short duration and high deficit volume for rain-to-snow-season droughts, and long duration and low deficit volume for wetto-dry-season droughts and composite droughts. Classical rainfall-deficit droughts, cold snow season droughts, and warm snow season droughts show large overlap. Most events of these types have relatively short durations and low to intermediate deficit volumes. Hence, although processes underlying these drought types are different, drought characteristics are comparable.

In Fig. 12, the same discharge drought events are plotted with more detail (one plot for each drought type and a different colour for quickly and slowly responding catchments). 

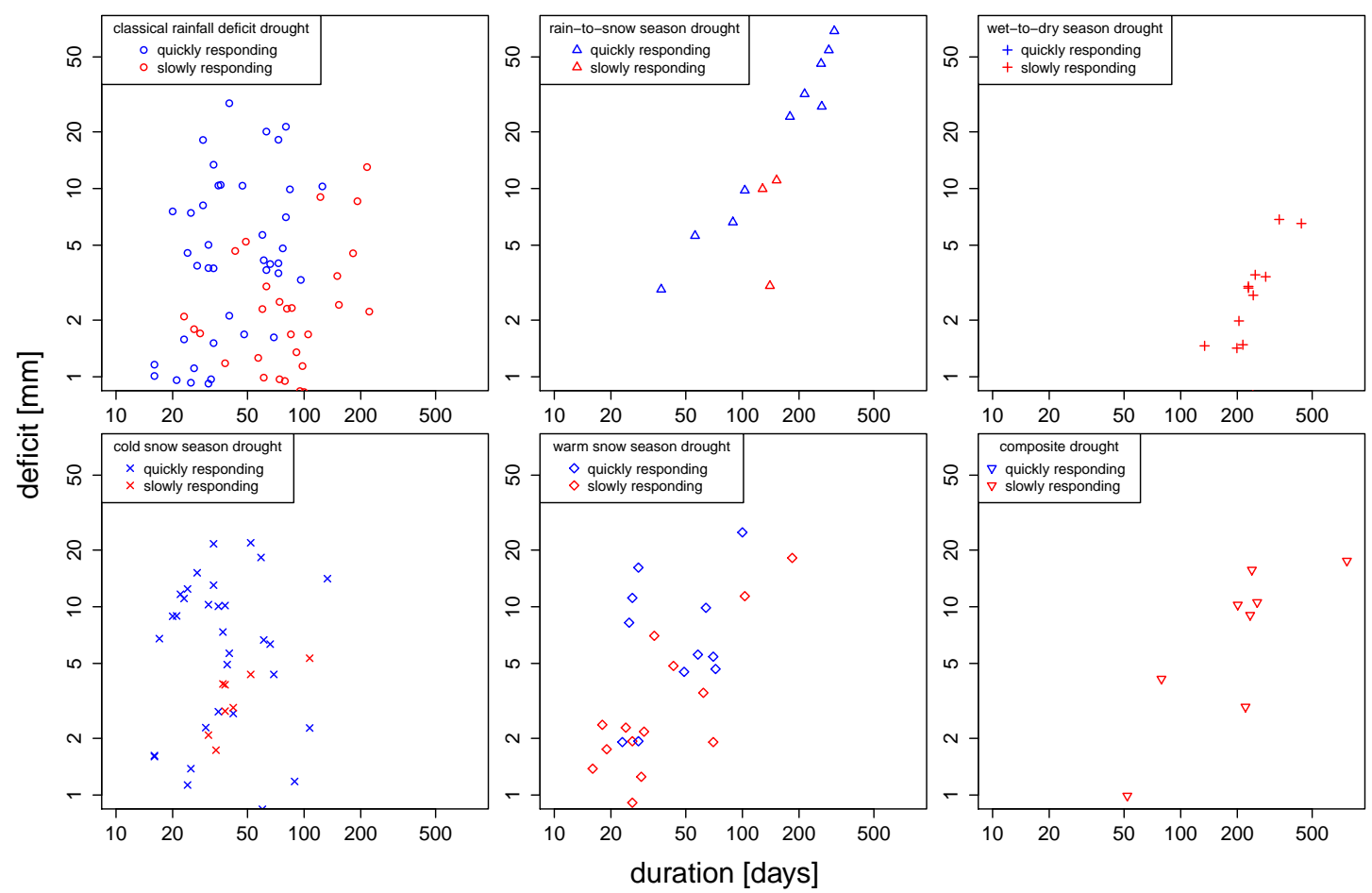

Fig. 12. Drought duration and deficit volume of all discharge drought events grouped per hydrological drought type, on log-log scale, differentiating between quickly and slowly responding catchments (quickly responding: Narsjø and Nedožery catchments; slowly responding: Upper-Metuje, Upper-Sázava, and Upper-Guadiana catchments).

For each drought type, the events in slowly responding catchments have, in general, somewhat longer durations and lower deficit volumes than those in quickly responding catchments. Wet-to-dry-season droughts and composite droughts were only found in slowly responding catchments. Composite droughts do not occur in quickly responding catchments. Wet-to-dry-season droughts presumably do occur in quickly responding catchments, but in this study no quickly responding catchment with semi-arid climate was included.

\subsection{Typology of most severe drought events}

Because Table 4 includes many small drought events that affect the distribution over the drought types, we selected the five most severe drought events for each catchment. The selection was done based on maximum deviation for groundwater and on deficit volume for discharge. Table 5 shows that the distribution of hydrological drought events over the different drought types changed significantly after this selection. The classical rainfall deficit drought is represented less in most catchments (in total for all catchments together, from 22 to $12 \%$ in groundwater, and from 43 to $32 \%$ in discharge; not shown). The cold snow season drought disappeared almost completely from the list, because this drought type usually has low deficit volumes. A large part of the most severe drought events are rain-to-snow-season droughts (up to $80 \%$ for the Narsjø catchment). The reason is that these droughts are usually very long and can build up a large deficit volume. For the same reason composite droughts are more represented in the most severe drought events.

When drought events are classified according to their duration and the five longest drought events are selected, the distribution over the drought types is similar to Table 5 (not shown).

Based on Table 5, we can conclude that the most severe hydrological droughts are:

- in snow catchments: rain-to-snow-season drought and warm snow season drought;

- in semi-arid climates: wet-to-dry-season drought;

- in quickly responding catchments: classical rainfall deficit drought;

- in slowly responding catchments: composite drought.

The cold snow season drought occurs regularly, but is usually not severe.

\section{$5.3 \quad$ Non-drought development}

Up to now, we only discussed situations in which meteorological droughts developed into hydrological droughts. For process understanding and drought management, it is also 

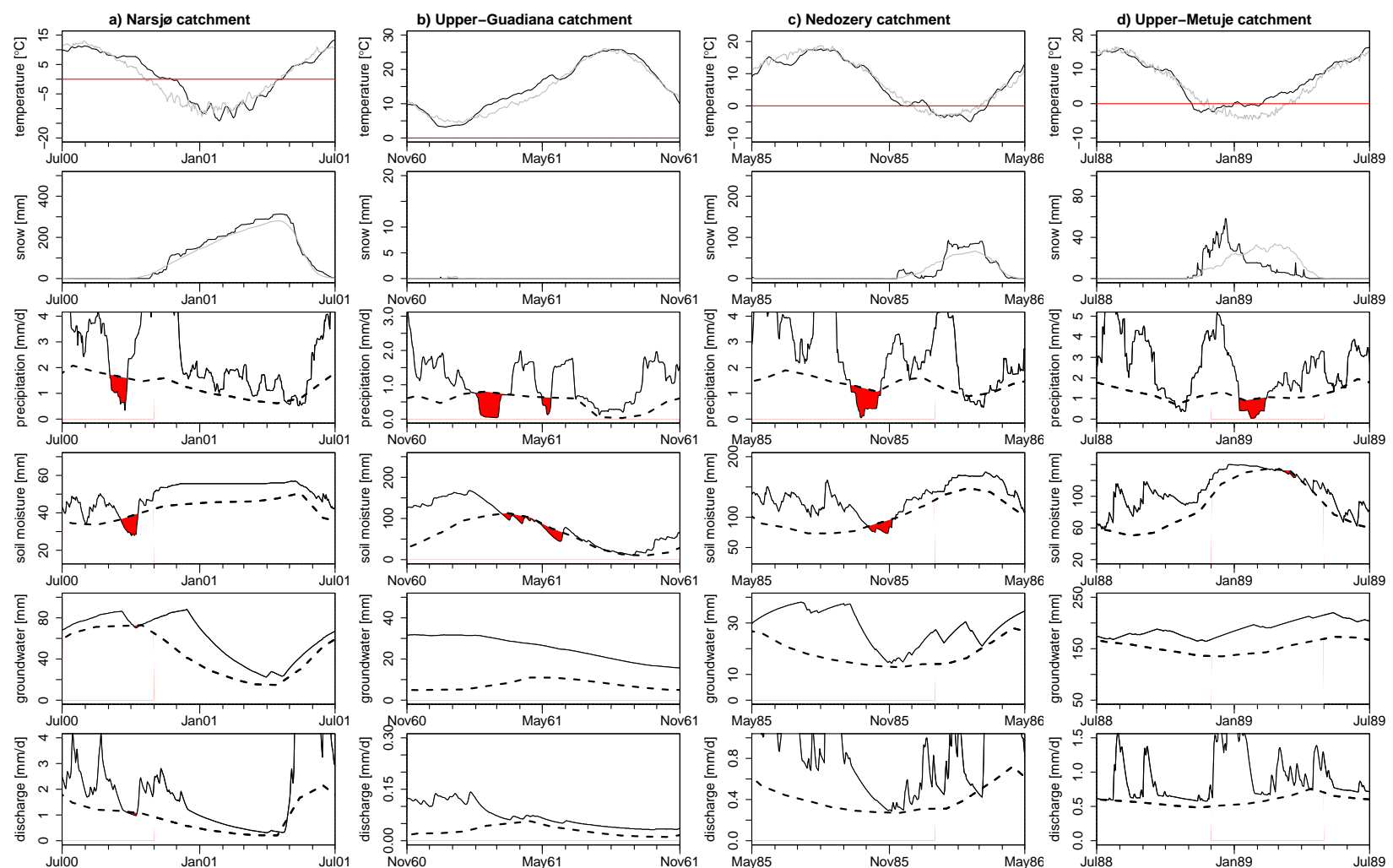

Fig. 13. Examples of non-drought events: (a) Narsjø catchment 2000-2001, (b) Upper-Guadiana catchment 1960-1961, (c) Nedožery catchment 1985-1986, (d) Upper-Metuje catchment 1988-1989 (legend: see Fig. 5).

relevant to study situations when a hydrological drought did not develop. Why did a rainfall deficit not propagate through the hydrological cycle? Which processes are involved that buffer or counteract the drought?

In snow climates, a number of processes can prevent a hydrological drought from developing. One example is the situation that a rainfall deficit in the spring season coincides with the snow melt period. In that case, no hydrological drought will develop, because water availability is very high. If this same rainfall deficit would have occurred a few months later, a classical rainfall deficit drought would have developed. On the other hand, a warm winter and an early snow melt could lead to a warm snow season drought-subtype A, but not if it is combined with very high rainfall amounts during the normal snow melt season (Sect. 4.5). A warm winter can also have another effect in snow climates - namely a late start of the snow season (Sect. 4.5). This can prevent a rain-to-snowseason drought from developing. An example is shown in Fig. 13a (Narsjø catchment). The rainfall deficit in September 2000 (3rd panel) resulted in just below-threshold levels in groundwater storage and discharge (5th and 6th panel). If temperatures would have dropped below zero in October, like they normally do, the precipitation peak in OctoberNovember 2000 (3rd panel) would have fallen as snow and groundwater storage and discharge would have stayed below the threshold until the next snow melt season. In this case, however, temperature dropped below zero only at the end of November (1st panel), hence the aforementioned precipitation peak could alleviate the hydrological drought, and the meteorological drought did not develop into a rain-to-snowseason drought.

In slowly responding catchments, attenuation is a wellknown drought propagation feature (Fig. 1). Meteorological drought events are often attenuated in the stores and no hydrological drought develops. An example is shown in Fig. 13b (Upper-Guadiana catchment). The rainfall deficit in February 1961 (3rd panel) led to a drought in soil moisture (4th panel) and to a decrease in groundwater levels and discharge (5th and 6th panel), but high groundwater storage prevented both variables from falling below threshold level. If antecedent storage would have been low, a wet-to-dry-season drought would have developed, like in the examples in Fig. 7. Attenuation of a meteorological drought can also occur in quickly responding catchments, but only after a very wet period (e.g. after extensive rainfall or snow melt). The rainfall deficit in September-October 1985 in Fig. 13c (Nedožery catchment; 3rd panel) would have developed into a classical rainfall deficit drought, but due to the very wet condition of the catchment after extensive rainfall in the previous months 
Table 6. Drought propagation processes per hydrological drought type and occurrence in Köppen-Geiger major climate types.

\begin{tabular}{llll}
\hline Hydrological drought type & Governing process(es) & $P$-control/T-control & Climate type \\
\hline Classical rainfall deficit drought & Rainfall deficit (in any season) & $P$-control & A, B, C, D, E \\
Rain-to-snow-season drought & Rainfall deficit in rain season, drought continues into snow season & $P$ and $T$-control & C, D, E \\
Wet-to-dry-season drought & Rainfall deficit in wet season, drought continues into dry season & $P$ and $T$-control & A, B, C \\
Cold snow season drought & Low temperature in snow season, leading to: & & \\
$\quad$ Subtype A & Early beginning of snow season & $T$-control & D, E \\
Subtype B & Delayed snow melt & $T$-control & D, E \\
Subtype C & No recharge & $T$-control & C, D \\
Warm snow season drought & High temperature in snow season, leading to: & $P$ and $T$-control & D, E \\
Subtype A & Early snow melt & $P$ and/or $T$-control & A, B, C, D, E \\
Subtype B & In combination with rainfall deficit, no recharge & & \\
Composite drought & Combination of a number of drought events over various seasons & &
\end{tabular}

(5th and 6th panel), the recession of groundwater storage and discharge did not drop below the threshold level.

Also a combination of processes can prevent a meteorological drought from developing into a hydrological drought. The example in Fig. 13d (Upper-Metuje catchment) could have become a warm snow season drought (above-zero temperatures in the snow season, melt of the snow cover, and, additionally, a rainfall deficit in January 1989), but the snow melt peak had increased groundwater storage and discharge to such high levels that the warm and dry winter did not have much effect.

From these examples, we learn that both precipitation and temperature, and antecedent storage in the catchment, are important factors that can prevent a hydrological drought from developing.

\section{Discussion}

\subsection{Typology}

In this paper, we proposed a hydrological drought typology based on drought propagation processes. Table 6 summarises the governing processes of the six hydrological drought types.

Because division into types is based on the interpretation of time series of hydro-meteorological variables, the boundaries between drought types are not sharp. Subjective choices cannot be avoided, for example when several processes are involved in the development of a hydrological drought event. This is not a major drawback, as the typology should be used for process understanding, to study differences between catchments, and as a general tool for drought management. Therefore, the exact number of drought events of a certain type for a specific catchment is not relevant, but rather the general occurrence of drought types in a catchment and the drought type of the most severe drought events. We propose that for events where more processes play a role, the dominant one determines the drought type.

The drought propagation features on which the typology is based, are determined by climate and catchment control (see
Sect. 1). In Sects. 3.2.2, 4, and 5, these controls have already been used to describe drought characteristics, different hydrological drought types, and the occurrence of these types in the study catchments. In the following sections, catchment and climate control and their relation with the defined hydrological drought types are discussed in more detail.

\subsection{Catchment control}

For drought propagation, catchment control is very important. Lag and attenuation, but also pooling and lengthening, are determined by catchment characteristics like geology (Vogel and Kroll, 1992; Mishra and Singh, 2010), area (Rossi et al., 1992; Byzedi and Saghafian, 2009), mean slope, and percentage of lakes and forest (Demuth and Young, 2004). These propagation features are represented in all hydrological drought types, but show up most prominently in composite droughts. In Sect. 5, we saw that composite droughts only occur in slowly responding catchments and that this drought type is amongst the most severe events. The governing factor is a catchment's reaction to precipitation, which is mainly determined by the amount of storage in the catchment. This storage can be in groundwater (like in Upper-Metuje and Upper-Guadiana catchments), in lakes (like in Upper-Sázava catchment), or in bogs (like in Narsjø catchment).

It is very striking that in catchments with high storage, where a very smooth discharge signal is expected, peaks in discharge still often occur as a reaction to a precipitation event (see Figs. 9 and 10). These peaks interrupt the drought event, but do not lead to full recovery from the drought. After the peak, discharge returns to its very low values. This was also found by Woo and Tariiule (1994), who state that "brief inter-event streamflow rises will seldom ameliorate a drought event". Pooling is therefore a crucial step in drought analysis to prevent separation of drought events that are actually caused by the same process.

Figure 14 shows that the composite drought is the only drought type that is primarily controlled by catchment characteristics (the $\mathrm{x}$-axis in Fig. 14). The other drought types are mainly controlled by climate (the y-axis in Fig. 14). 


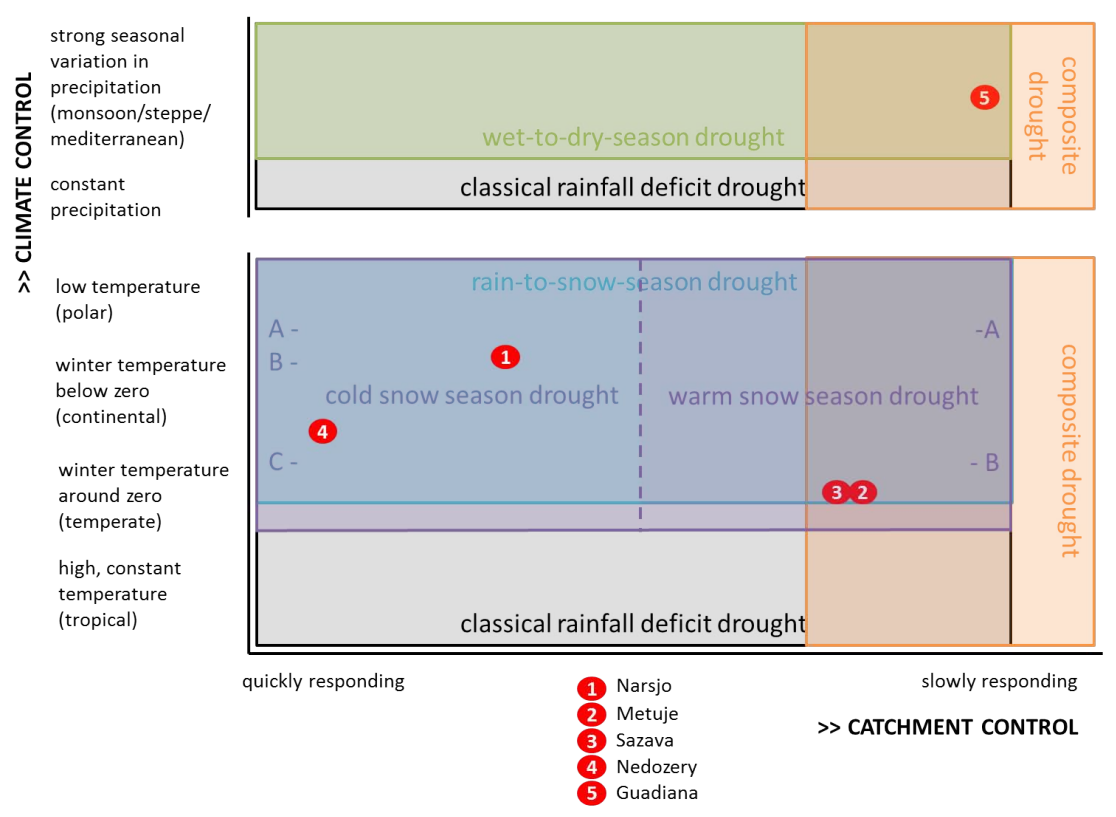

Fig. 14. Hydrological drought (sub-)type occurrence in relation to catchment and climate control. Catchment control is indicated by a slower response of discharge to precipitation when moving from left to right on the $\mathrm{x}$-axis. Climate control is indicated by describing temperature and precipitation regimes relevant for drought development: temperature on the lower part of the y-axis, precipitation on the upper part of the y-axis (desert and glacier climates are not included, as is it not relevant to speak of droughts in these climates, WMO, 2008). The five study catchments are included based on their climate and catchment characteristics (see Sect. 2); for explanation of the drought (sub-)types see Table 6.

\subsection{Climate control}

The effect of climate on hydrological drought types is divided into the influence of general climatology and the influence of the weather pattern.

General climatology - the general climatology determines the occurrence of specific drought types in certain regions (Stahl and Hisdal, 2004; Sheffield and Wood, 2007) and is governed by climatic variables like mean annual temperature and mean annual precipitation (Rossi et al., 1992; Demuth and Young, 2004). The occurrence of drought types in climate regions is indicated in Sect. 4, Table 6 (last column), and Fig. 14 (y-axis). Classical rainfall deficit droughts occur in all climates and wet-to-dry-season droughts only in climates with strong seasonal variation in precipitation. The three snow-related drought types occur in a similar range of climates from temperate to continental and polar (Fig. 14).

The hydrological drought typology is developed using five catchments with different climate in Europe. These catchments are indicted in Fig. 14, based on their climate and catchment characteristics. The papers mentioned in Sect. 4 could not be included in Fig. 14, because insufficient information on catchment and climate control was provided. Because the typology is based on generally observable processes, it can be used in catchments that fall outside the reach of the studied catchments (for example in the upper-left part of Fig. 14). Adding more catchments with different climate and catchment characteristics to the framework of Fig. 14 is an interesting way forward in drought research. Focus can then be on e.g. tropical climates and quickly responding catchments in steppe or monsoon climates. This can be achieved using data of real catchments or synthetic data, following the approach of Van Lanen et al. (2012). This newlydeveloped approach also allows for a better quantification of the effect of catchment and climate control on drought propagation and drought typology.

Weather pattern - the weather pattern determines the development of a hydrological drought event of a certain type in a certain catchment. Precipitation and temperature are key variables. Table 6 shows whether the hydrological drought types are determined by precipitation ( $P$-control), temperature ( $T$-control), or a combination of precipitation and temperature ( $P$ and $T$-control).

By studying hydrological droughts in different catchments, we found that the influence of precipitation is different in different regions. In (semi-)arid climates, for example, long-term precipitation amounts are important. Rainfall in these climates is little and very irregular. A relatively dry period can last for years or decades (Vicente-Serrano and López-Moreno, 2006), leading to very low storage. Composite droughts are the result. Also, in other catchments, we found that droughts tend to cluster in time: periods with few drought events alternate with periods with many drought events, which is consistent with other studies (Stahl and Hisdal, 2004; Uhlemann et al., 2010). In Central Europe, for example, the first half of the 1980s, the 1990s, and the 
2000s were dry periods and the periods in between were relatively wet (Tallaksen and Van Lanen, 2004). This clustering of meteorological droughts is important for propagation. An isolated meteorological drought might be attenuated in the stores (Sect. 5.3), but a number of successive meteorological droughts decrease storage and a severe hydrological drought can develop. In that light, not only low precipitation events are important for the development of hydrological drought. Also high precipitation events should be included in drought analysis, as they can prevent a drought from developing due to high storage in the catchment (see Sect. 5.3), or cause the end of a drought (in case of drought types not related to snow, e.g. Sect. 4.1).

A sustained lack of precipitation is usually governed by large-scale circulation patterns. Therefore, many studies that focus on hydrological drought include atmospheric circulation patterns, e.g. correlation with ENSO (Kingston et al., 2010; Lavers et al., 2010), weather types (Phillips and McGregor, 1998; Fowler and Kilsby, 2002; Fleig et al., 2010, 2011), and blocking high-pressure areas (Stahl and Demuth, 1999; Stahl, 2001; Stahl and Hisdal, 2004; Pfister et al., 2006). These large-scale circulation patterns determine the timing of a precipitation event and whether it is high or low, which is crucial for drought development.

Temperature is also determined by large-scale circulation patterns (Domonkos et al., 2003; Xoplaki et al., 2003), but because the development of snow-related hydrological drought types is very sensitive to a narrow temperature range around zero, elevation also plays an important role in those drought types. Two catchments in the same region can have different drought type occurrence when they have a different elevation. For example, in the higher catchment a rain-tosnow-season drought can develop because precipitation already falls in the form of snow, while in the lower catchment the hydrological drought ceases due to rainfall. Synchronicity of droughts within a region, therefore, mainly happens with drought types that are precipitation controlled (i.e. classical rainfall deficit drought and wet-to-dry-season drought) and less with those that are temperature controlled (i.e. rain-to-snow-season drought, cold snow season drought, and warm snow season drought). In catchments with a large elevation range, variability of drought development within the catchment can occur, as the timing of when and for how long temperatures decrease below zero is variable within the catchment. A large elevation range is also the reason that discharge peaks can occur when the catchment-average temperature is still below zero.

In this study, potential evaporation was found not to be a major factor governing the development of different hydrological drought types. The reason is that even in situations when potential evaporation is higher than normal, actual evaporation is low due to lack of water available for evaporation. In regions with very high water availability (e.g. some subtypes of Köppen-Geiger climate type A) an increase in potential evaporation might have more influence
(Van Lanen et al., 2004). For the presented drought typology, potential evaporation is only important in a climatic perspective: in catchments with a season in which potential evaporation is higher than precipitation, wet-to-dry-season droughts can occur.

In many papers, a distinction is made between summer and winter droughts. The term summer drought is mostly used referring to classical rainfall deficit drought. The term winter drought, however, is less clear. It covers a number of drought types (rain-to-snow-season drought, cold snow season drought, warm snow season drought, or even classical rainfall deficit drought), and drought generating processes are not well addressed if winter drought is defined as a drought in the winter half of the year (Pfister et al., 2006).

Climate change will probably lead to a change in occurrence of drought types (Feyen and Dankers, 2009), because in a higher temperature regime the Köppen-Geiger climate regions will shift to higher latitudes and higher elevations and the associated hydrological drought types will shift along. This can have strong implications for drought management. For example, a drought type that is normally ended by a snow melt peak might change into a drought type that can continue into summer (Van Loon et al., 2010).

\section{Conclusions}

In this paper, we proposed a general hydrological drought typology based on underlying processes of drought propagation. The typology can be used in research and management. Drought research could benefit from a common terminology, which can also guide further study of the processes underlying drought. Drought management is supported because different drought types need different preventing measures and coping mechanisms. The hydrological drought types that are distinguished are: (i) classical rainfall deficit drought, (ii) rain-to-snow-season drought, (iii) wet-to-dryseason drought, (iv) cold snow season drought, (v) warm snow season drought, and (vi) composite drought.

- Classical rainfall deficit droughts are caused by a rainfall deficit (in any season) and occur in all climate types.

- Rain-to-snow-season droughts are caused by a rainfall deficit in the rain season, after which the hydrological drought continues into the snow season because temperatures have decreased below zero, and occur in catchments with a pronounced snow season.

- Wet-to-dry-season droughts are caused by a rainfall deficit in the wet season, after which the hydrological drought continues into the dry season, when potential evaporation is much higher than precipitation, and occur in catchments with pronounced wet and dry seasons.

- Cold snow season droughts are caused by a low temperature in the snow season. In catchments with a very 
cold winter, subtypes A and B occur, which are caused by an early beginning of the snow season and a delayed snow melt, respectively. In catchments with temperatures around zero in winter, subtype $\mathrm{C}$ occurs, which is caused by a lack of recharge due to snow accumulation.

- Warm snow season droughts are caused by a high temperature in the snow season. In catchments with a very cold winter, subtype A occurs, which is caused by an early snow melt. In catchments with temperatures around zero in winter, subtype B occurs, which is caused by a complete melt of the snow cover in combination with a subsequent rainfall deficit.

- Composite droughts are caused by a combination of hydrological drought events (of the same or different drought types) over various seasons and can occur in all climate types, but are most likely in (semi-)arid climates and slowly responding catchments.

About 125 groundwater droughts and 210 discharge droughts of five contrasting headwater catchments in Europe have been classified using the developed topology. The most common drought type in all catchments was the classical rainfall deficit drought (almost $50 \%$ of all events), but these are mostly minor events. When only the five most severe drought events of each catchment were considered, a shift towards more rain-to-snow-season droughts, warm snow season droughts, and composite droughts was found. The occurrence of drought types is determined by climate and catchment characteristics. The typology is transferable to catchments outside Europe, because it is generic and based upon processes that occur around the world. A general framework is proposed that enables identification of the occurrence of hydrological drought types in relation to climate and catchment characteristics. Herewith, we hope to contribute to process understanding of drought propagation and improvement of drought forecasting and management all around the world.

\section{Appendix A}

\section{HBV model validation}

For drought studies, it would be most desirable to have long (tens of years), complete time series of observed fluxes and state variables. Unfortunately, these data were not available for this study and are in general very rare, in particular for sufficiently contrasting catchments. The main purpose of using a model in this research was the simulation of state variables (snow accumulation, soil moisture, groundwater storage) for which no long time series exist. For the Upper-Guadiana catchment, modelling was also required to naturalize the disturbed time series (Sect. 3.1). In this appendix, we present a validation of the model on discharge and groundwater by comparing simulations with observations using graphs of time series and annual and monthly values of the 50th and 80th percentile of the duration curves. Additionally, a summary of the validation of snow and soil moisture from previously published reports is given.

For the Narsjø catchment, model results showed the highest $\ln$ Reff (0.90; Table 2). This is due to the very regular seasonal pattern of discharge, dominated by yearly recurring winter low-flow conditions (Fig. A1 - upper panel), that can be captured quite well with a rainfall-runoff model like HBV (Van Loon et al., 2010).

This regular seasonal pattern is also visible in the groundwater levels in the Narsjø catchment (Fig. A2 - upper panel). Groundwater in this catchment had a good fit to observations, as can be seen from the percentiles in Table A1. The coefficient of determination, $r^{2}$, was quite high with 0.72 , and visual comparison indicated a good ability of the model to reproduce the general dynamics of the groundwater table (Fig. A2 - upper panel). Soil moisture was measured close to but outside of the Narsj $\varnothing$ catchment on a location that is not fully representative for the Narsjø, but the measurements can be used to validate the temporal dynamics of the simulations (Hohenrainer, 2008). Simulated soil moisture percentiles showed a reasonable agreement to the percentiles of observations (Table A1, upper rows), although the coefficient of determination was quite low $\left(r^{2}=0.35\right)$. The reason for this low value is deviations in winter, i.e. decreasing observed values vs. constant simulated values (not shown). This is partly because the TDR probes measured available water content which is lower than stored water content due to soil frost (Hohenrainer, 2008), and partly because HBV does not simulate outflow from the soil moisture store when evaporation is zero (Fig. 3). Hohenrainer (2008), who used the HBV model with similar settings, calibration procedure and objective function, stated that the onset and duration of drought periods were captured reasonably well by the model, justifying the use of simulated soil moisture and groundwater series for drought analysis.

For the Upper-Metuje, Upper-Sázava, and Nedožery catchments, $\ln$ Reff was around 0.65 (Table 2). This is lower than the value for the Narsjø catchment, because seasonal variation is much more irregular in these catchments (Fig. A1 -2 nd, 3rd and 4th panels). Figure A1 shows that the hydrographs of Upper-Metuje and Nedožery are better reproduced than that of Upper-Sázava. However, the yearly and monthly percentiles of Upper-Sázava are reasonable (Table A1).

For the Upper-Metuje catchment, a validation against observed groundwater levels was performed. The coefficient of determination was high $\left(r^{2}=0.79\right)$ and the yearly and monthly percentiles show similar values (Table A1). Visual comparison indicated a good ability of the model to reproduce the general dynamics of the groundwater table (Fig. A2 - 2nd panel).

For the Upper-Sázava catchment, both snow storage and groundwater simulations were validated. For groundwater, the coefficient of determination was quite low $\left(r^{2}=0.46\right)$. This is probably due to the lack of representativeness of the 


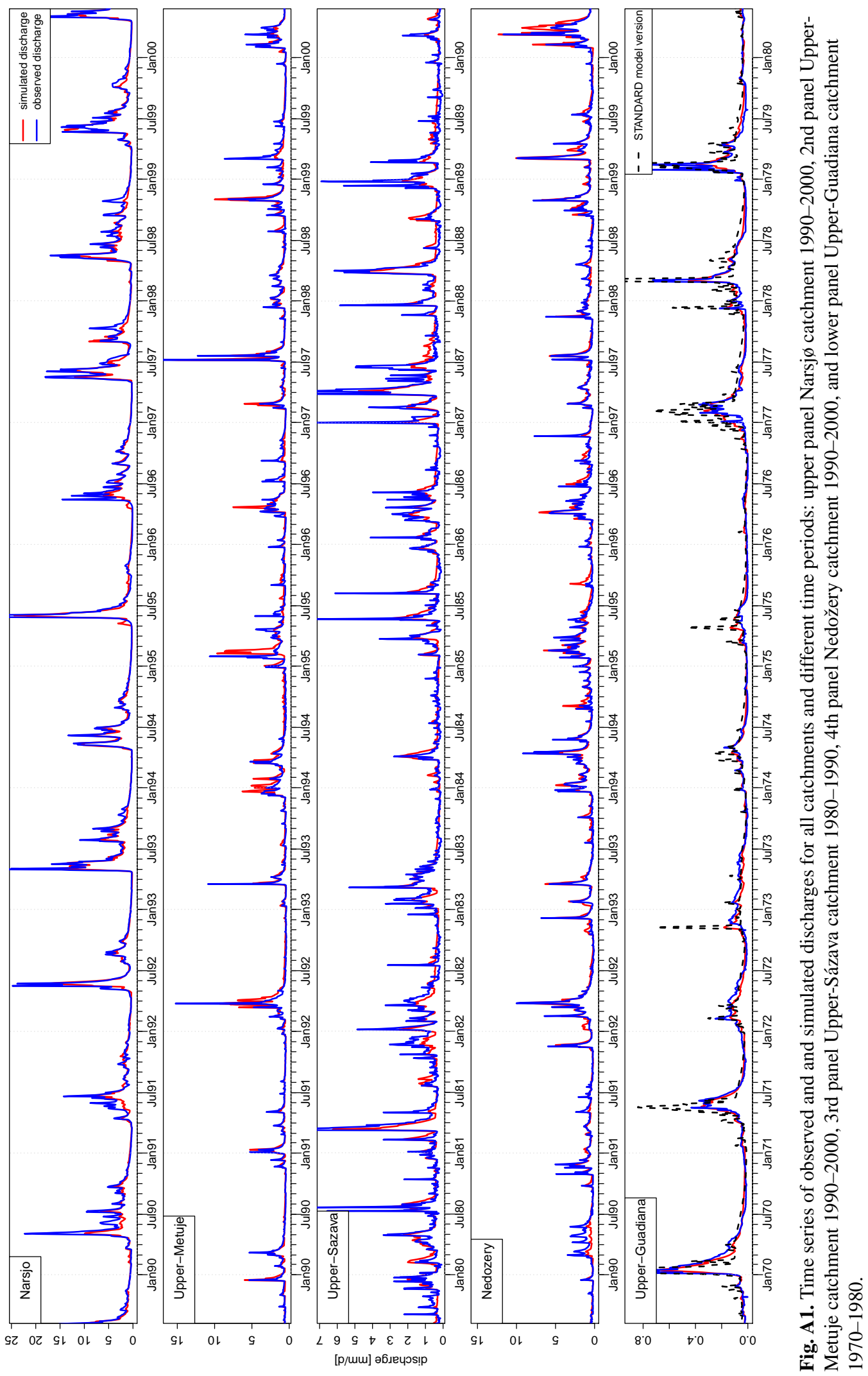




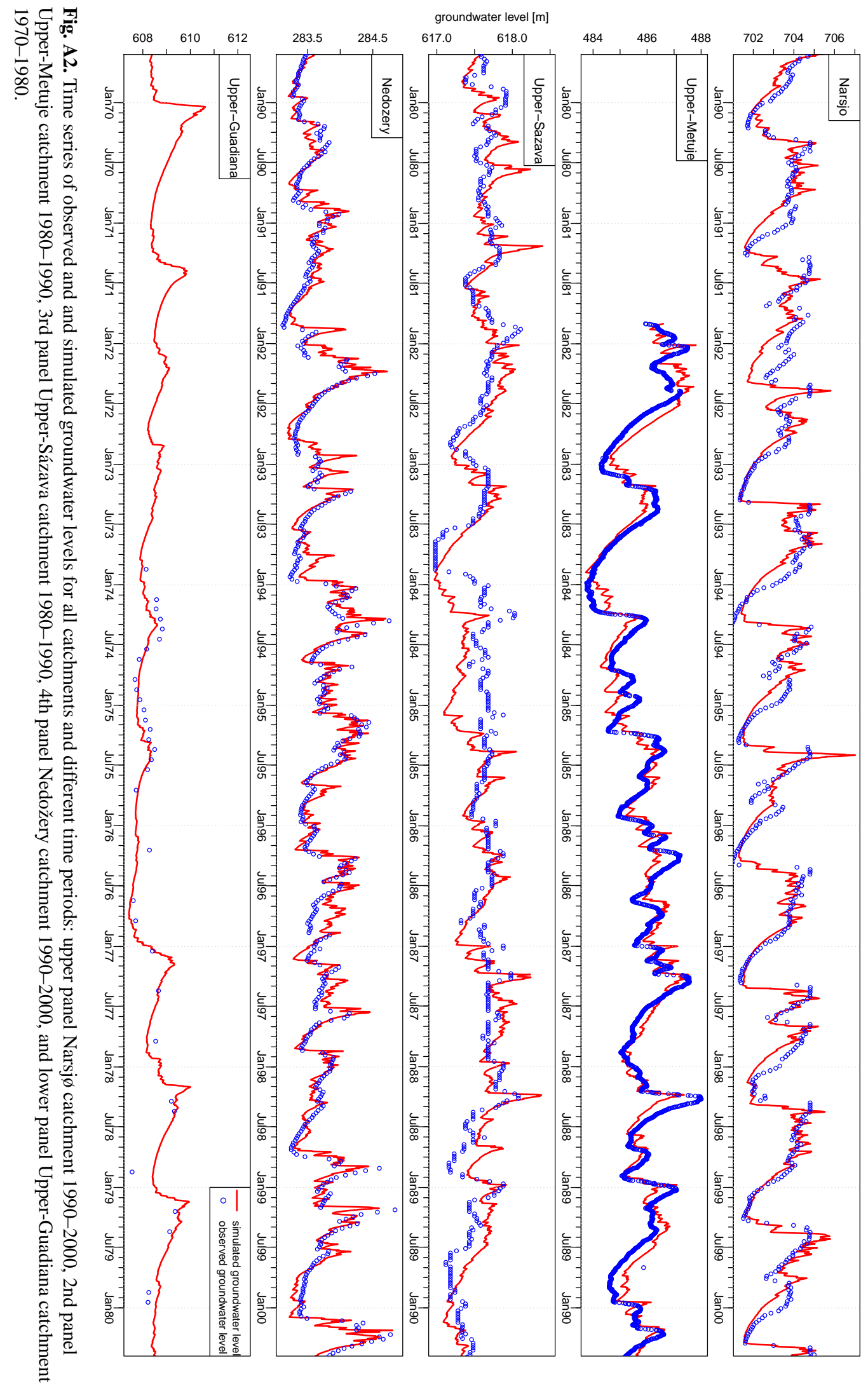


Table A1. Annual and monthly values of the 50th and 80th percentile of the duration curves of soil moisture (only Narsjø), groundwater and discharge.

\begin{tabular}{|c|c|c|c|c|c|c|c|c|c|c|c|c|c|c|c|}
\hline & & & Annual & Jan & Feb & Mar & Apr & May & Jun & Jul & Aug & Sep & Oct & Nov & Dec \\
\hline \multirow[t]{12}{*}{ Narsjø } & \multirow[t]{2}{*}{$\mathrm{SM}_{\text {sim }}$} & $50 \%$ & 0.2926 & 0.3013 & 0.3032 & 0.3051 & 0.3182 & 0.3393 & 0.2755 & 0.2553 & 0.259 & 0.2646 & 0.2814 & 0.2932 & 0.2979 \\
\hline & & $80 \%$ & 0.2584 & 0.2839 & 0.2858 & 0.287 & 0.297 & 0.3144 & 0.2322 & 0.2141 & 0.2092 & 0.2254 & 0.2503 & 0.2721 & 0.2783 \\
\hline & \multirow[t]{2}{*}{$\mathrm{SM}_{\mathrm{obs}}$} & $50 \%$ & 0.28 & 0.25 & 0.255 & 0.26 & 0.29 & 0.49 & 0.34 & 0.29 & 0.24 & 0.28 & 0.28 & 0.28 & 0.26 \\
\hline & & $80 \%$ & 0.22 & 0.15 & 0.16 & 0.16 & 0.2222 & 0.464 & 0.278 & 0.23 & 0.15 & 0.238 & 0.26 & 0.24 & 0.172 \\
\hline & \multirow[t]{2}{*}{$\mathrm{GW}_{\text {sim }}$} & $50 \%$ & 703.1 & 702.1 & 701.8 & 701.6 & 701.6 & 703.9 & 703.9 & 703.8 & 703.9 & 703.9 & 703.7 & 703.1 & 702.5 \\
\hline & & $80 \%$ & 701.8 & 701.9 & 701.6 & 701.5 & 701.5 & 702.9 & 703.5 & 703.3 & 703.4 & 703.4 & 703.3 & 702.8 & 702.2 \\
\hline & \multirow[t]{2}{*}{$\mathrm{GW}_{\mathrm{obs}}$} & $50 \%$ & 703.5 & 702.7 & 702.3 & 701.9 & 701.8 & 704.8 & 704.4 & 703.8 & 703.5 & 703.6 & 703.8 & 703.7 & 703.6 \\
\hline & & $80 \%$ & 702.1 & 702 & 701.7 & 701.4 & 701.2 & 704.7 & 704.1 & 703.5 & 702.4 & 702.2 & 703.3 & 703.3 & 702.6 \\
\hline & \multirow[t]{2}{*}{$Q_{\text {sim }}$} & $50 \%$ & 1.04 & 0.487 & 0.354 & 0.271 & 0.3005 & 5.152 & 3.191 & 2.213 & 2.013 & 1.809 & 1.402 & 0.985 & 0.6945 \\
\hline & & $80 \%$ & 0.388 & 0.396 & 0.2892 & 0.2148 & 0.207 & 1.68 & 2.149 & 1.471 & 1.205 & 1.161 & 1.058 & 0.8114 & 0.5698 \\
\hline & \multirow{2}{*}{$Q_{\mathrm{obs}}$} & $50 \%$ & 1.046 & 0.45 & 0.342 & 0.279 & 0.284 & 6.56 & 4.353 & 2.229 & 1.895 & 1.91 & 1.883 & 1.164 & 0.706 \\
\hline & & $80 \%$ & 0.36 & 0.36 & 0.279 & 0.223 & 0.223 & 2.511 & 2.52 & 1.227 & 0.883 & 1.101 & 1.141 & 0.868 & 0.553 \\
\hline \multirow[t]{8}{*}{ Upper-Metuje } & \multirow[t]{2}{*}{$\mathrm{GW}_{\text {sim }}$} & $50 \%$ & 485.6 & 485.4 & 485.6 & 486.1 & 486.1 & 486 & 485.8 & 485.6 & 485.5 & 485.3 & 485.2 & 485.2 & 485.1 \\
\hline & & $80 \%$ & 484.9 & 484.5 & 484.9 & 485.1 & 485.6 & 485.5 & 485.4 & 485.2 & 485 & 484.8 & 484.6 & 484.4 & 484.4 \\
\hline & \multirow[t]{2}{*}{$\mathrm{GW}_{\mathrm{obs}}$} & $50 \%$ & 485.6 & 485.4 & 485.6 & 486.2 & 486.8 & 486.4 & 486 & 485.5 & 485.2 & 485.2 & 485.2 & 484.9 & 485.2 \\
\hline & & $80 \%$ & 484.7 & 484.3 & 484.9 & 485.1 & 486 & 485.7 & 485.5 & 485 & 484.7 & 484.4 & 484.2 & 484 & 484.2 \\
\hline & \multirow{2}{*}{$Q_{\mathrm{sim}}$} & $50 \%$ & 0.687 & 0.845 & 0.8085 & 1.334 & 1.181 & 0.724 & 0.6785 & 0.661 & 0.625 & 0.6285 & 0.594 & 0.5955 & 0.653 \\
\hline & & $80 \%$ & 0.563 & 0.535 & 0.587 & 0.6508 & 0.7618 & 0.651 & 0.614 & 0.593 & 0.5698 & 0.541 & 0.508 & 0.483 & 0.514 \\
\hline & \multirow[t]{2}{*}{$Q_{\mathrm{obs}}$} & $50 \%$ & 0.686 & 0.803 & 0.8405 & 1.291 & 1.186 & 0.773 & 0.645 & 0.602 & 0.566 & 0.581 & 0.557 & 0.582 & 0.648 \\
\hline & & $80 \%$ & 0.523 & 0.546 & 0.557 & 0.743 & 0.8936 & 0.654 & 0.5494 & 0.523 & 0.4898 & 0.492 & 0.47 & 0.474 & 0.5116 \\
\hline \multirow[t]{8}{*}{ Upper-Sázava } & \multirow[t]{2}{*}{$\mathrm{GW}_{\text {sim }}$} & $50 \%$ & 617.5 & 617.5 & 617.5 & 617.7 & 617.7 & 617.7 & 617.6 & 617.6 & 617.5 & 617.5 & 617.4 & 617.4 & 617.4 \\
\hline & & $80 \%$ & 617.3 & 617.2 & 617.2 & 617.4 & 617.5 & 617.5 & 617.4 & 617.4 & 617.4 & 617.3 & 617.2 & 617.2 & 617.2 \\
\hline & \multirow{2}{*}{$\mathrm{GW}_{\mathrm{obs}}$} & $50 \%$ & 617.5 & 617.6 & 617.6 & 617.7 & 617.7 & 617.6 & 617.5 & 617.5 & 617.5 & 617.4 & 617.3 & 617.5 & 617.6 \\
\hline & & $80 \%$ & 617.3 & 617.4 & 617.4 & 617.5 & 617.5 & 617.4 & 617.4 & 617.3 & 617.2 & 617.2 & 617.2 & 617.2 & 617.4 \\
\hline & \multirow[t]{2}{*}{$Q_{\text {sim }}$} & $50 \%$ & 0.426 & 0.411 & 0.5965 & 0.954 & 1.024 & 0.4895 & 0.427 & 0.4115 & 0.4045 & 0.37 & 0.344 & 0.339 & 0.3845 \\
\hline & & $80 \%$ & 0.316 & 0.2834 & 0.336 & 0.4134 & 0.5678 & 0.3814 & 0.35 & 0.333 & 0.317 & 0.297 & 0.27 & 0.2548 & 0.277 \\
\hline & \multirow{2}{*}{$Q_{\mathrm{obs}}$} & $50 \%$ & 0.494 & 0.58 & 0.6745 & 1.218 & 1.08 & 0.632 & 0.441 & 0.366 & 0.3455 & 0.402 & 0.355 & 0.375 & 0.5285 \\
\hline & & $80 \%$ & 0.27 & 0.263 & 0.3102 & 0.4666 & 0.5936 & 0.329 & 0.2686 & 0.2296 & 0.211 & 0.237 & 0.213 & 0.237 & 0.296 \\
\hline \multirow[t]{8}{*}{ Nedožery } & \multirow[t]{2}{*}{$\mathrm{GW}_{\mathrm{sim}}$} & $50 \%$ & 283.7 & 283.7 & 283.7 & 283.8 & 283.9 & 283.8 & 283.7 & 283.7 & 283.6 & 283.6 & 283.5 & 283.6 & 283.6 \\
\hline & & $80 \%$ & 283.5 & 283.5 & 283.5 & 283.7 & 283.8 & 283.7 & 283.6 & 283.5 & 283.5 & 283.5 & 283.4 & 283.4 & 283.5 \\
\hline & $\mathrm{GW}_{\mathrm{obs}}$ & $50 \%$ & 283.7 & 283.7 & 283.8 & 283.9 & 283.9 & 283.8 & 283.7 & 283.6 & 283.6 & 283.5 & 283.5 & 283.5 & 283.6 \\
\hline & & $80 \%$ & 283.5 & 283.5 & 283.6 & 283.7 & 283.8 & 283.7 & 283.6 & 283.5 & 283.4 & 283.4 & 283.3 & 283.4 & 283.4 \\
\hline & $Q_{\text {sim }}$ & $50 \%$ & 0.588 & 0.568 & 0.6425 & 1.403 & 1.283 & 0.671 & 0.5965 & 0.548 & 0.448 & 0.4545 & 0.39 & 0.4575 & 0.521 \\
\hline & & $80 \%$ & 0.361 & 0.3114 & 0.4132 & 0.5584 & 0.7214 & 0.5274 & 0.4418 & 0.386 & 0.3264 & 0.292 & 0.277 & 0.2708 & 0.31 \\
\hline & $Q_{\mathrm{obs}}$ & $50 \%$ & 0.598 & 0.682 & 0.7815 & 1.559 & 1.425 & 0.823 & 0.577 & 0.448 & 0.355 & 0.326 & 0.365 & 0.46 & 0.601 \\
\hline & & $80 \%$ & 0.328 & 0.446 & 0.4604 & 0.8234 & 0.9148 & 0.572 & 0.3888 & 0.287 & 0.221 & 0.212 & 0.239 & 0.298 & 0.368 \\
\hline Upper-Guadiana & $\mathrm{GW}_{\text {sim }}$ & $50 \%$ & 608.2 & 608.3 & 608.4 & 608.4 & 608.4 & 608.4 & 608.3 & 608.1 & 608 & $\mathrm{NA}^{*}$ & 607.8 & 607.9 & 608 \\
\hline (1960-1980) & & $80 \%$ & 607.7 & 607.8 & 607.8 & 607.8 & 607.9 & 607.9 & 607.8 & 607.7 & 607.6 & $\mathrm{NA}^{*}$ & 607.5 & 607.6 & 607.7 \\
\hline & $\mathrm{GW}_{\mathrm{obs}}$ & $50 \%$ & 608.3 & 608.2 & 608.3 & 608.4 & 608.7 & 608.8 & 608.5 & 608.2 & 607.7 & $\mathrm{NA}^{*}$ & 607.7 & 607.9 & 608.1 \\
\hline & & $80 \%$ & 607.9 & 608.1 & 608.2 & 608.3 & 608.4 & 608.6 & 608.4 & 608.2 & 607.7 & $\mathrm{NA}^{*}$ & 607.7 & 607.7 & 607.9 \\
\hline & $Q_{\text {sim }}$ & $50 \%$ & 0.044 & 0.0735 & 0.091 & 0.118 & 0.094 & 0.065 & 0.05 & 0.036 & 0.02801 & 0.028 & 0.028 & 0.032 & 0.037 \\
\hline & & $80 \%$ & 0.023 & 0.0268 & 0.043 & 0.05 & 0.057 & 0.04 & 0.031 & 0.022 & 0.015 & 0.012 & 0.011 & 0.021 & 0.022 \\
\hline & $Q_{\mathrm{obs}}$ & $50 \%$ & 0.04 & 0.0755 & 0.098 & 0.136 & 0.103 & 0.076 & 0.051 & 0.025 & 0.014 & 0.013 & 0.016 & 0.022 & 0.036 \\
\hline & & $80 \%$ & 0.015 & 0.035 & 0.047 & 0.048 & 0.063 & 0.051 & 0.036 & 0.016 & 0.008 & 0.007 & 0.01 & 0.015 & 0.021 \\
\hline
\end{tabular}

$*=$ not enough groundwater observations to determine percentiles for Guadiana in September.

groundwater well for groundwater storage in the entire catchment. Actually, most of the catchment consists of crystalline rock, whereas the groundwater well is located in sedimentary rocks. Furthermore, some measurement problems were recorded at this well (Rakovec et al., 2009). This results in deficiencies in reproducing the time series of observed groundwater levels (Fig. A2 - 3rd panel), but the yearly and monthly percentiles are still very similar (Table A1). The reason for this difference is that an incorrect simulation of the timing of high and low flows is not reflected in the percentiles in (Table A1), while it has a large impact on the coefficient of determination. For snow, the coefficient of determination was reasonable $\left(r^{2}=0.57\right)$. The general pattern of the simulation agrees well with observed values (not shown, see Rakovec et al., 2009).
For the Nedožery catchment, both snow storage and groundwater simulations were validated. For groundwater, the coefficient of determination was high $\left(r^{2}=0.74\right)$ and the yearly and monthly percentiles also showed similar values (Table A1). Visual inspection of the time series of observed and simulated groundwater levels showed that the general dynamics of the groundwater table were reproduced rather well (Fig. A2 - 4th panel). For snow, visual comparison between simulated and observed snow cover showed that the model was able to simulate snow in the correct period and with the correct amount (not shown, see Oosterwijket al., 2009).

For the Upper-Guadiana catchment, the numbers in $\mathrm{Ta}-$ ble 2 were obtained with the DELAY version of the HBV model (Sect. 3.1 and Fig. 3) for the calibration and validation period combined (1960-1980). Model results of 
the STANDARD version, which was used for the other catchments, showed a lower $\ln$ Reff than those of the DELAY version (0.51 instead of 0.71). A visual inspection of time series of the two model versions confirmed that the DELAY version reproduced recessions best. It showed less peaky behaviour and no zero-flows as compared to the STANDARD version (Fig. A1 - lower panel). Therefore, the results of the DELAY version were used for further analysis in the UpperGuadiana catchment. In the other catchments, Nash-Sutcliffe values and visual inspection of time series revealed that the DELAY version had less agreement with observations (not shown). The good results of the Upper-Guadiana model in the calibration and validation period (both undisturbed, see Table 1) justify the extrapolation of the model to the disturbed period (i.e. naturalization of disturbed time seriesfor the period after 1980; Van Loon and Van Lanen, 2012).

For the Upper-Guadiana catchment, a validation against observed groundwater levels was performed in part of the undisturbed period for which data was available. In this catchment, many groundwater observation wells have been installed. Some of the wells showed quite a poor correlation with simulated values, but the well with best correlation had an $r^{2}$ value of 0.83 . Visual comparison indicated a good ability of the model to reproduce the general dynamics of the groundwater table, although the data points in the undisturbed period were limited (Fig. A2 - lower panel). Also, Table A1 showed that intra-annual variation in groundwater levels was reproduced well by the model.

In summary, we can conclude that the performance of the HBV model in the study catchments is acceptable for drought analysis, as was also found by Van Huijgevoort et al. (2010) and Van Loon et al. (2010), and hence for the identification of different hydrological drought types.

Acknowledgements. This research was undertaken as part of the European Union (FP6) funded Integrated Project Water and Global Change (WATCH, contract no. 036946). It is part of the programme of the Wageningen Institute for Environment and Climate Research (WIMEK-SENSE) and it supports the work of the UNESCO-IHP VII FRIEND programme. Part of the funding was provided by the European Union (FP7) project DROUGHT-R \& SPI (contract no. 282769). We thank Jan Seibert for providing the HBV light model, and NVE (Norway), TGM-WRI (Czech Republic), Comenius University (Slovakia), and UCLM and AEMET (Spain) for providing hydro-meteorological data of the study catchments. Furthermore, we acknowledge MSc-students Olda Rakovec, Jacob Oosterwijk, and Durk Veenstra for assistance in modelling and Remko Uijlenhoet for fruitful discussion and comments to the manuscript. Finally, we thank the reviewers, G. Laguardia and R. Woods, and the handling editor, A. Gelfan, for their valuable comments.

Edited by: A. Gelfan

\section{References}

Acreman, M.: Guidelines for the sustainable management of groundwater-fed catchments in Europe, GRAPES: Groundwater and River Resources Action Programme on a European Scale, Institute of Hydrology, Wallingford, 2000.

Akhtar, M., Ahmad, N., and Booij, M. J.: The impact of climate change on the water resources of Hindukush-KarakorumHimalaya region under different glacier coverage scenarios, J. Hydrol., 355, 148-163, doi:10.1016/j.jhydrol.2008.03.015, 2008.

Allen, R. G., Pereira, L. S., and Raes, D.: Crop evapotranspiration: guidelines for computing crop water requirements, FAO irrigation and drainage papers no. 56, FAO, Rome, 1998.

Andreadis, K. M., Clark, E. A., Wood, A. W., Hamlet, A. F., and Lettenmaier, D. P.: Twentieth-century drought in the conterminous United States, J. Hydrometeorol., 6, 985-1001, doi:10.1175/JHM450.1, 2005.

Below, R., Grover-Kopec, E., and Dilley, M.: Documenting drought-related disasters: a global reassessment, J. Environ. Develop., 16, 328-344, doi:10.1177/1070496507306222, 2007.

Bergström, S.: The HBV model, Water Resources Publications, Colorado, 443-476, 1995.

Bergström, S.: Development and application of a conceptual runoff model for Scandinavian catchments, SMHI Reports RHO No. 7, Ph.D. thesis, 1976.

Bierkens, M. F. P. and van den Hurk, B. J. J. M.: Groundwater convergence as a possible mechanism for multi-year persistence in rainfall, Geophys. Res. Lett., 34, 3104-3121, doi:10.1029/2006GL028396, 2007.

Birkel, C.: Temporal and Spatial Variability of Drought Indices in Costa Rica, Master's thesis, Albert-Ludwigs-Universität, Freiburg, Germany, 2005.

Bonacci, O.: Hydrological identification of drought, Hydrol. Process., 7, 249-262, doi:10.1002/hyp.3360070303, 1993.

Byzedi, M. and Saghafian, B.: Regional analysis of streamflow drought: a case study for Southwestern Iran, in: Proceedings of World Academy of Science, Engineering and Technology, 57, 447-451, 2009.

CRED: EM-DAT: The OFDA/CRED International Disaster Database, available at: http://www.emdat.be (last access: 10 October 2011), Université catholique de Louvain, Brussels, Belgium, 2011.

Dai, A.: Drought under global warming: a review, Wiley Interdisciplinary Reviews: Climate Change, 2, 45-65, doi:10.1002/wcc.81, 2011

de la Hera, A.: Analysis hidrologico de los humedales de la Mancha Humeda, Ph.D. thesis, Universidad Complutense de Madrid, 1998.

Demuth, S. and Young, A. R.: Regionalization procedures, in: Hydrological Drought, Processes and Estimation Methods for Streamflow and Groundwater, edited by: Tallaksen, L. M. and Van Lanen, H. A. J., Development in Water Science 48, Elsevier Science B.V., 307-343, 2004.

Di Domenico, A., Laguardia, M., and Margiotta, M.: Investigating the propagation of droughts in the water cycle at the catchment scale, in: International Workshop Advances in statistical hydrology, 23-25 May 2010, Taormina, Italy, 2010.

Domonkos, P., Kyselý, J., Piotrowicz, K., Petrovic, P., and Likso, T.: Variability of extreme temperature events in South-central Eu- 
rope during the 20th century and its relationship with large-scale circulation, Int. J. Climatol., 23, 987-1010, doi:10.1002/joc.929, 2003.

Doorenbos, J. and Pruitt, W. O.: Guidelines for predicting crop water requirements, FAO Irrigation and drainage papers no. 24, FAO, Rome, monograph Omslagtitel: Crop water requirements, Wageningen UR Library, 1975.

Dracup, J. A., Kil Seong, L., and Paulson Jr., E. G.: On the definition of droughts, Water Resour. Res., 16, 297-302, 1980.

Driessen, T. L. A., Hurkmans, R. T. W. L., Terink, W., Hazenberg, P., Torfs, P. J. J. F., and Uijlenhoet, R.: The hydrological response of the Ourthe catchment to climate change as modelled by the HBV model, Hydrol. Earth Syst. Sci., 14, 651-665, doi:10.5194/hess-14-651-2010, 2010.

Eltahir, E. A. B. and Yeh, P. J.-F.: On the asymmetric response of aquifer water level to floods and droughts in Illinois, Water Resour. Res., 35, 1199-1217, 1999.

Engeland, K.: ECOMAG - Application to the Upper Glomma catchment, Tech. rep., Department of Geosciences, University of Oslo, Norway, 2002.

Engeland, K., Hisdal, H., and Frigessi, A.: Practical Extreme Value Modelling of Hydrological Floods and Droughts: A Case Study, Extremes, 7, 5-30, 2004.

EU: Water Scarcity and Droughts - Second Interim Report, European Commission, DG Environment, Brussels, 2006.

EU: Addressing the challenge of water scarcity and droughts in the European Union, Communication from the commission to the European Parlement and the Council, European Commission, DG Environment, Brussels, 2007.

FEWS-NET: EAST AFRICA: Past year one of the driest on record in the eastern Horn, available at: http://www.fews.net, last access: 5 October 2011.

Feyen, L. and Dankers, R.: Impact of global warming on streamflow drought in Europe, J. Geophys. Res., 114, D17116, doi:10.1029/2008jd011438, 2009.

Fleig, A. K., Tallaksen, L. M., Hisdal, H., and Demuth, S.: A global evaluation of streamflow drought characteristics, Geophys. Res. Abstr., EGU05-A-04287, EGU General Assembly 2005, Vienna, Austria, 2005.

Fleig, A. K., Tallaksen, L. M., Hisdal, H., and Demuth, S.: A global evaluation of streamflow drought characteristics, Hydrol. Earth Syst. Sci., 10, 535-552, doi:10.5194/hess-10-535-2006, 2006.

Fleig, A. K., Tallaksen, L. M., Hisdal, H., Stahl, K., and Hannah, D. M.: Inter-comparison of weather and circulation type classifications for hydrological drought development, Phys. Chem. Earth, 35, 507-515, 2010.

Fleig, A. K., Tallaksen, L. M., Hisdal, H., and Hannah, D. M.: Regional hydrological drought in North-Western Europe: linking a new Regional Drought Area Index with weather types, Hydrol. Process., 25, 1163-1179, 2011.

Fowler, H. J. and Kilsby, C. G.: A weather-type approach to analysing water resource drought in the Yorkshire region from 1881 to 1998 , J. Hydrol., 262, 177-192, doi:10.1016/S00221694(02)00034-3, 2002.

Heim Jr., R.: A review of twentieth-century drought indices used in the United States, B. Am. Meteorol. Soc., 83, 1149-1165, 2002.

Hisdal, H.: Regional aspects of drought, Ph.D. thesis, Faculty of Mathematics and Natural Sciences, University of Oslo, Norway, 2002.
Hisdal, H. and Tallaksen, L.: Drought Event Definition, Tech. rep., ARIDE Technical Report No. 6, University of Oslo, Norway, 2000.

Hisdal, H., Stahl, K., Tallaksen, L. M., and Demuth, S.: Have streamflow droughts in Europe become more severe or frequent?, Int. J. Climatol., 21, 317-333, 2001.

Hisdal, H., Tallaksen, L. M., Clausen, B., Peters, E., and Gustard, A.: Hydrological drought characteristics, in: Hydrological Drought. Processes and Estimation Methods for Streamflow and Groundwater, edited by: Tallaksen, L. M. and Van Lanen, H., Developments in Water Science 48, Elsevier Science B.V, 139-198, 2004.

Hohenrainer, J.: Propagation of drought through the hydrological cycle in two different climatic regions, Master's thesis, AlbertLudwigs-Universität, Freiburg, Germany, 121 pp., 2008.

ISDR: Drought Risk Reduction Framework and Practices: Contributing to the Implementation of the Hyogo Framework for Action, United Nations secretariat of the International Strategy for Disaster Reduction (UNISDR), Geneva, Switzerland, 213 pp., 2007.

Kaznowska, E. and Banasik, K.: Streamflow droughts and probability of their occurrence in a small agricultural catchment, Annals of Warsaw University of Life Sciences - SGGW - Land Reclamation, No. 43, 2011.

Keyantash, J. and Dracup, J. A.: The quantification of drought: an evaluation of drought indices, B. Am. Meteorol. Soc., 83, 11671180, 2002.

Kim, D.-W., Byun, H.-R., Choi, K.-S., and Oh, S.-B.: A spatiotemporal analysis of historical droughts in Korea, J. Appl. Meteorol. Clim., 50, 1895-1912, doi:10.1175/2011JAMC2664.1, 2011.

Kingston, D. G., Fleig, A. K., Tallaksen, L. M., and Hannah, D. M.: North Atlantic sea surface temperature, atmospheric circulation and summer drought in Great Britain, in: 6th World FRIEND Conference "Global Change: Facing Risks and Threats to Water Resources”, edited by: Servat, E., Demuth, S., Dezetter, A., Daniell, T., Ferrari, E., Ijjaali, M., Jabrane, R., Van Lanen, H., and Huang, Y., IAHS-AISH P., 340, 598-604, 2010.

Krause, P., Boyle, D. P., and Bäse, F.: Comparison of different efficiency criteria for hydrological model assessment, Adv. Geosci., 5, 89-97, doi:10.5194/adgeo-5-89-2005, 2005.

Lavers, D., Prudhomme, C., and Hannah, D. M.: Large-scale climate, precipitation and British river flows: identifying hydroclimatological connections and dynamics, J. Hydrol., 395, 242255, doi:10.1016/j.jhydrol.2010.10.036, 2010.

Li, J., Cook, E., Chen, F., Gou, X., D'Arrigo, R., and Yuan, Y.: An extreme drought event in the Central Tien Shan area in the year 1945, J. Arid Environ., 74, 1225-1231, doi:10.1016/j.jaridenv.2010.03.002, 2010.

Lidén, R. and Harlin, J.: Analysis of conceptual rainfall-runoff modelling performance in different climates, J. Hydrol., 238, 231247, doi:10.1016/S0022-1694(00)00330-9, 2000.

Lindström, G.: A simple automatic calibration routine for the HBV model, Nord. Hydrol., 28, 153-168, 1997.

Lloyd-Hughes, B. and Saunders, M. A.: A drought climatology for Europe, Int. J. Climatol., 22, 1571-1592, 2002.

Marsh, T., Cole, G., and Wilby, R.: Major droughts in England and Wales, 1800-2006, Weather, 62, 87-93, doi:10.1002/wea.67, 2007. 
McKee, T. B., Doesken, N., and Kleist, J.: The relationship of drought frequency and duration to time scales, in: Eight Conference on Applied Climatology, Amer. Meteor. Soc., 179-184, 1993.

McKee, T. B., Doesken, N. J., and Kleist, J.: Drought monitoring with multiple time scales, in: Ninth Conference On Applied Climatology, Amer. Meteor. Soc., 233-236, 1995.

Merz, R. and Blöschl, G.: A process typology of regional floods, Water Resour. Res., 39, 1340, doi:10.1029/2002WR001952, 2003.

Merz, R. and Blöschl, G.: Regionalisation of catchment model parameters, J. Hydrol., 287, 95-123, doi:10.1016/j.jhydrol.2003.09.028, 2004.

Mishra, A. K. and Singh, V. P.: A review of drought concepts, J. Hydrol., 391, 202-216, doi:10.1016/j.jhydrol.2010.07.012, 2010.

Mpelasoka, F., Hennessy, K., Jones, R., and Bates, B.: Comparison of suitable drought indices for climate change impacts assessment over Australia towards resource management, Int. J. Climatol., 28, 1283-1292, doi:10.1002/joc.1649, 2008.

Nash, J. E. and Sutcliffe, J. V.: River flow forecasting through conceptual models part I - A discussion of principles, J. Hydrol., 10, 282-290, 1970.

Niemeyer, S.: New drought indices, in: Drought Management: Scientific and Technological Innovations, in: Proceedings of the 1st International Conference "Drought management: Scientific and technological innovations", 267-274, 2008.

NRK: http://nrk.no/nyheter/distrikt/hedmark_og_oppland/1. 7007900 (last access: 10 October 2011), Norwegian Broadcasting Corporation, 2010.

Ntale, H. K. and Gan, T. Y.: Drought indices and their application to East Africa, Int. J. Climatol., 23, 1335-1357, doi:10.1002/joc.931, 2003.

Nützmann, G. and Mey, S.: Model-based estimation of runoff changes in a small lowland watershed of North-eastern Germany, J. Hydrol., 334, 467-476, doi:10.1016/j.jhydrol.2006.10.026, 2007.

Oosterwijk, J., Van Loon, A. F., Machlica, A., Horvát, O., Van Lanen, H. A. J., and Fendeková, M.: Hydrological drought characteristics of the Nedožerysubcatchment, Upper Nitra, Slovakia, based on HBV modelling, WATCH Technical Report 20, Wageningen University, the Netherlands, available at: http://www. eu-watch.org/publications/technical-reports (last access: 19 December 2011), 2009.

Oudin, L., Michel, C., Andréassian, V., Anctil, F., and Loumagne, C.: Should Bouchet's hypothesis be taken into account in rainfall-runoff modelling? An assessment over 308 catchments, Hydrol. Process., 19, 4093-4106, 2005.

Pandey, R., Mishra, S., Singh, R., and Ramasastri, K.: Streamflow Drought Severity Analysis of Betwa River System (India), Water Resour. Manag., 22, 1127-1141, 2008.

Perrin, C., Michel, C., and Andréassian, V.: Does a large number of parameters enhance model performance? Comparative assessment of common catchment model structures on 429 catchments, J. Hydrol., 242, 275-301, doi:10.1016/S0022-1694(00)00393-0, 2001.

Peters, E., Torfs, P. J. J. F., Van Lanen, H. A. J., and Bier, G.: Propagation of drought through groundwater - a new approach using linear reservoir theory, Hydrol. Process., 17, 3023-3040, 2003.
Pfister, C., Weingartner, R., and Luterbacher, J.: Hydrological winter droughts over the last 450 years in the Upper Rhine basin: a methodological approach, Hydrolog. Sci. J., 51, 966-985, 2006.

Phillips, I. D. and McGregor, G. R.: The utility of a drought index for assessing the drought hazard in Devon and Cornwall, South West England, Meteorol. Appl., 5, 359-372, doi:10.1017/S1350482798000899, 1998.

Rakovec, O., Van Loon, A. F., Horáček, S., Kašpárek, L., Van Lanen, H. A. J., and Novický, O.: Drought analysis for the Upper Metuje and Upper Sázava catchments (Czech Republic) using the hydrological model HBV, WATCH Technical Report 19, Wageningen University, the Netherlands, available at: http://www. eu-watch.org/publications/technical-reports (last access: 19 December 2011), 2009.

Rossi, G., Benedini, M., Tsakiris, G., and Giakoumakis, S.: On regional drought estimation and analysis, Water Resour. Manag., 6, 249-277, 1992.

Santos, J., Corte-real, J., and Leite, S.: Atmospheric large-scale dynamics during the 2004/2005 winter drought in Portugal, Int. J. Climatol., 27, 571-586, doi:10.1002/joc.1425, 2007.

Seibert, J.: Estimation of parameter uncertainty in the HBV model, Nord. Hydrol., 28, 247-262, 1997.

Seibert, J.: Regionalisation of parameters for a conceptual rainfallrunoff model, Agr. Forest Meteorol., 98-9, 279-293, 1999.

Seibert, J.: Multi-criteria calibration of a conceptual runoff model using a genetic algorithm, Hydrol. Earth Syst. Sci., 4, 215-224, doi:10.5194/hess-4-215-2000, 2000.

Seibert, J.: HBV Light - User's manual, Department of Physical Geography and Quaternary Geology, Stockholm University, available at: http://people.su.se/ jseib/HBV/HBV_manual_2005.pdf (last access: 5 December 2011), 2005.

Seibert, J., Rodhe, A., and Bishop, K.: Simulating interactions between saturated and unsaturated storage in a conceptual runoff model, Hydrol. Process., 17, 379-390, doi:10.1002/hyp.1130, 2003.

Sheffield, J.: Global drought in the 20th and 21st centuries: analysis of retrospective simulations and future projections of soil moisture, Ph.D. thesis, Wageningen University, The Netherlands, 2008.

Sheffield, J. and Wood, E. F.: Characteristics of global and regional drought, 1950-2000: analysis of soil moisture data from off-line simulation of the terrestrial hydrologic cycle, J. Geophys. Res.Atmos., 112, D17115, doi:10.1029/2006JD008288, 2007.

Sheffield, J. and Wood, E. F.: Drought, Past Problems and Future Scenarios, Earthscan, 2011.

Sheffield, J., Andreadis, K. M., Wood, E. F., and Lettenmaier, D. P.: Global and continental drought in the second half of the twentieth century: severity-area-duration analysis and temporal variability of large-scale events, J. Climate, 22, 1962-1981, 2009.

Smakhtin, V. U.: Low flow hydrology: a review, J. Hydrol., 240, 147-186, 2001.

Smakhtin, V. U. and Hughes, D. A.: Review, Automated Estimation and Analyses of Drought Indices in South Asia, Working paper 83, drought series paper 1, International Water Management Institute, Colombo, Sri Lanka, 2004.

Stahl, K.: Hydrological Drought - a Study across Europe, Ph.D. thesis, Albert-Ludwigs-Universität, Freiburg, Germany, 2001. 
Stahl, K. and Demuth, S.: Linking streamflow drought to the occurrence of atmospheric circulation patterns, Hydrolog. Sci. J., 44, 467-482, doi:10.1080/02626669909492240, 1999.

Stahl, K. and Hisdal, H.: Hydroclimatology, in: Hydrological Drought. Processes and Estimation Methods for Streamflow and Groundwater, edited by: Tallaksen, L. M. and Van Lanen, H., Developments in Water Science 48, Elsevier Science B.V., 19-51, 2004.

Staudinger, M., Stahl, K., Seibert, J., Clark, M. P., and Tallaksen, L. M.: Comparison of hydrological model structures based on recession and low flow simulations, Hydrol. Earth Syst. Sci., 15, 3447-3459, doi:10.5194/hess-15-3447-2011, 2011.

Tallaksen, L. M. and Van Lanen, H. A. J.: Hydrological drought: processes and estimation methods for streamflow and groundwater, Developments in Water Science 48, Elsevier Science B.V., The Netherlands, 2004.

Tallaksen, L. M., Madsen, H., and Clausen, B.: On the definition and modelling of streamflow drought duration and deficit volume, Hydrolog. Sci. J., 42, 15-33, 1997.

Tallaksen, L. M., Hisdal, H., and van Lanen, H. A. J.: Space-time modelling of catchment scale drought characteristics, J. Hydrol., 375, 363-372, 2009.

Tate, E. L. and Freeman, S. N.: Three modelling approaches for seasonal streamflow droughts in southern Africa: the use of censored data, Hydrolog. Sci. J., 45, 27-42, doi:10.1080/02626660009492304, 2000.

te Linde, A. H., Aerts, J. C. J. H., Hurkmans, R. T. W. L., and Eberle, M.: Comparing model performance of two rainfall-runoff models in the Rhine basin using different atmospheric forcing data sets, Hydrol. Earth Syst. Sci., 12, 943-957, doi:10.5194/hess-12-9432008, 2008.

Trigo, R. M., Gouveia, C., and Barriopedro, D.: The intense 20072009 drought in the Fertile Crescent: impacts and associated atmospheric circulation, Agr. Forest Meteorol., 150, 1245-1257, doi:10.1016/j.agrformet.2010.05.006, 2010.

Trigo, R. M., Pereira, J. M. C., Pereira, M. G., Mota, B., Calado, T. J., Dacamara, C. C., and Santo, F. E.: Atmospheric conditions associated with the exceptional fire season of 2003 in Portugal, Int. J. Climatol., 26, 1741-1757, 2006.

Uhlemann, S., Thieken, A. H., and Merz, B.: A consistent set of trans-basin floods in Germany between 1952-2002, Нydrol. Earth Syst. Sci., 14, 1277-1295, doi:10.5194/hess-14-12772010, 2010.

Uhlenbrook, S., Seibert, J., Leibundgut, C., and Rodhe, A.: Prediction uncertainty of conceptual rainfall-runoff models caused by problems in identifying model parameters and structure, Hydrolog. Sci. J., 44, 779-797, 1999.

UN: Humanitarian Requirements for the Horn of Africa Drought 2011, available at: http://ochaonline.un.org/humanitarianappeal/ webpage.asp?Page=1955 (last access: 25 October 2011), 2011.

Van Huijgevoort, M. H. J., Van Loon, A. F., Rakovec, O., Haddeland, I., Horáček, S., and Van Lanen, H. A. J.: Drought assessment using local and large-scale forcing data in small catchments, in: 6th World FRIEND Conference "Global Change: Facing Risks and Threats to Water Resources", edited by: Servat, E., Demuth, S., Dezetter, A., Daniell, T., Ferrari, E., Ijjaali, M., Jabrane, R., Van Lanen, H., and Huang, Y., IAHS-AISH P., 340, 77-85, 2010.
Van Lanen, H. A. J., Fendeková, M., Kupczyk, E., Kasprzyk, A., and Pokojski, W.: Flow Generating Processes, in: Hydrological Drought, Processes and Estimation Methods for Streamflow and Groundwater, edited by: Tallaksen, L. M. and Van Lanen, H. A. J., Development in Water Science 48, Elsevier Science B.V., 53-96, 2004.

Van Lanen, H. A. J., Tallaksen, L. M. Candel, M., Carrera, J., Crooks, S., Engeland, K., Fendeková, M., Haddeland, I., Hisdal, H., Horacek, S., Jódar Bermúdez, J., Van Loon, A. F., Machlica, A., Navarro, V., Novický, O., and Prudhomme, C.: Database with hydrometeorological variables for selected river basins: Metadata Catalogue, WATCH Technical Report 4, Wageningen University, The Netherlands, available at: http://www.eu-watch.org/ publications/technical-reports (last access: 19 December 2011), 2008.

Van Lanen, H. A. J., Wanders, N., Tallaksen, L. M., and Van Loon, A. F.: Hydrological drought across the world: impact of hydroclimatology and physical catchment structure, Int. J. Climatol., under review, 2012.

Van Loon, A. F. and Van Lanen, H. A. J.: How to distinguish between water scarcity and drought?, to be submitted to Water Resour. Manag., 2012.

Van Loon, A. F., Fendeková, M., Hisdal, H., Horvát, O., Van Lanen, H. A. J., Machlica, A., Oosterwijk, J., and Tallaksen, L. M.: Understanding hydrological winter drought in $\mathrm{Eu}-$ rope, in: 6th World FRIEND Conference "Global Change: Facing Risks and Threats to Water Resources”, edited by: Servat, E., Demuth, S., Dezetter, A., Daniell, T., Ferrari, E., Ijjaali, M., Jabrane, R., Van Lanen, H. A. J., and Huang, Y., IAHS-AISH P., 340, 189-197, 2010.

Van Loon, A. F., Rakovec, O., and Van Lanen, H. A. J.: Processes behind multi-year droughts in catchments with seasonal climate and storage, Geophys. Res. Abstr., EGU2011-A-1904, EGU General Assembly 2011, Vienna, Austria, 2011a.

Van Loon, A. F., Van Lanen, H. A. J., Tallaksen, L. M., Hanel, M., Fendeková, M., Machlica, M., Sapriza, G., Koutroulis, A., Van Huijgevoort, M. H. J., Jódar Bermúdez, J., Hisdal, H., and Tsanis, I.: Propagation of drought through the hydrological cycle, WATCH Technical Report 31, Wageningen University, The Netherlands, available at: http://www.eu-watch.org/publications/ technical-reports (last access: 19 December 2011), 2011 b.

van Pelt, S. C., Kabat, P., ter Maat, H. W., van den Hurk, B. J. J. M., and Weerts, A. H.: Discharge simulations performed with a hydrological model using bias corrected regional climate model input, Hydrol. Earth Syst. Sci., 13, 2387-2397, doi:10.5194/hess13-2387-2009, 2009.

Veenstra, D.: Exploring drought in the Upper-Guadiana Basin, Spain, Master's thesis, Wageningen University, The Netherlands, 2009.

Vicente-Serrano, S. M. and López-Moreno, J. I.: The influence of atmospheric circulation at different spatial scales on winter drought variability through a semi-arid climatic gradient in Northeast Spain, Int. J. Climatol., 26, 1427-1453, 2006.

Vogel, R. M. and Kroll, C. N.: Regional geohydrologic-geomorphic relationships for the estimation of low-flow statistics, Water Resour. Res., 28, 2451-2458, doi:10.1029/92WR01007, 1992.

Wanders, N., Van Lanen, H. A. J., and Van Loon, A. F.: Indicators for drought characterization on a global scale, WATCH Technical Report 24, Wageningen University, The Netherlands, available 
at: http://www.eu-watch.org/publications/technical-reports (last access: 19 December 2011), 2010.

Wang, S., McGrath, R., Semmler, T., Sweeney, C., and Nolan, P.: The impact of the climate change on discharge of Suir River Catchment (Ireland) under different climate scenarios, Nat. Hazards Earth Syst. Sci., 6, 387-395, doi:10.5194/nhess-6-3872006, 2006.

Wilhite, D. A. and Glantz, M. H.: Understanding the drought phenomenon: the role of definitions, Water Int., 10, 111-120, 1985.

WMO: Manual on low flow estimation and prediction, Operational Hydrology Report No. 50, WMO-No. 1029, 136 pp., 2008.

Wong, W. K., Beldring, S., Engen-Skaugen, T., Haddeland, I., and Hisdal, H.: Climate Change Effects on Spatiotemporal Patterns of Hydroclimatological Summer Droughts in Norway, J. Hydrometeorol., 12, 1205-1220, doi:10.1175/2011JHM1357.1, 2011.
Woo, M.-K. and Tariiule, A.: Streamflow droughts of Northern Nigerian rivers, Hydrolog. Sci. J., 39, 19-34, 1994.

Xoplaki, E., González-Rouco, J. F., Luterbacher, J., and Wanner, H.: Mediterranean summer air temperature variability and its connection to the large-scale atmospheric circulation and SSTs, Clim. Dynam., 20, 723-739, doi:10.1007/s00382-003-0304-x, 2003.

Yevjevich, V.: An objective approach to definition and investigations of continental hydrologic droughts, Colorado State University, 1967.

Zelenhasić, E. and Salvai, A.: A method of streamflow drought analysis, Water Resour. Res., 23, 156-168, 1987. 